\title{
Structural refinement, Raman spectroscopy, optical and electrical properties of $\left(\mathrm{Ba}_{1-\mathrm{x}} \mathrm{Sr}_{\mathrm{x}}\right) \mathrm{MoO}_{4}$ ceramics
}

\author{
S. K. Ghosh ${ }^{1} \cdot$ S. K. Rout ${ }^{1} \cdot$ A. Tiwari ${ }^{1} \cdot$ P. $\operatorname{Yadav}^{1} \cdot$ J. C. Sczancoski ${ }^{2}$ \\ M. G. R. Filho ${ }^{3}$ L. S. Cavalcante ${ }^{3}$
}

Received: 3 May 2015/ Accepted: 14 July 2015 / Published online: 19 July 2015

(C) Springer Science+Business Media New York 2015

\begin{abstract}
In this paper, structural refinement, Raman spectroscopy, optical and electrical properties of barium strontium molybdate $\left[\left(\mathrm{Ba}_{1-x} \mathrm{Sr}_{x}\right) \mathrm{MoO}_{4}\right]$ ceramics with different $(x)$ contents $(x=0 ; 0.1 ; 0.2 ; 0.3 ; 0.4 ; 0.5 ; 0.6$; $0.7 ; 0.8 ; 0.9$; and 1 ) were synthesized by the solid state reaction method. These ceramics were structurally characterized by X-ray diffraction (XRD), Rietveld refinement, and micro-Raman spectroscopy. The shape of the grains for these ceramics was observed by means of scanning electron microscopy (SEM) images. The optical properties were investigated using ultraviolet-visible (UV-Vis) absorption spectroscopy and photoluminescence (PL) measurements. The dielectric and ferroelectric properties were analyzed by permittivity $\left(\varepsilon_{\mathrm{r}}\right)$, loss tangent $(\tan \delta)$ and polarization versus electric field (P-E) hysteresis loop. XRD patterns, Rietveld refinement, and micro-Raman spectra showed that all ceramics are monophasic with a scheelite-type tetragonal structure. A decreased of lattice parameters and unit cell volume was observed with the increase of $\mathrm{Sr}^{2+}$ ions into $\mathrm{BaMoO}_{4}$ lattice. Rietveld data were employed to model the $\left[\mathrm{BaO}_{8}\right],\left[\mathrm{SrO}_{8}\right]$ and $\left[\mathrm{MoO}_{4}\right]$ clusters in the tetragonal lattices. The SEM images indicate
\end{abstract}

S. K. Rout

skrout@bitmesra.ac.in

$\triangle$ L. S. Cavalcante

laeciosc@bol.com.br

1 Electroceramics Laboratory, Department of Physics, Birla Institute of Technology, Mesra, Ranchi, India

2 LIEC-IQ-Universidade Estadual Paulista, Araraquara, São Paulo 14801-907, Brazil

3 PPGQ-GERATEC-Universidade Estadual do Piauí, João Cabral, N. 2231, P.O. Box 381, Teresina, PI 64002-150, Brazil that increased $x$ content promotes a decrease in the grain size and modifications in the shape. UV-Vis spectra indicated a decrease in the optical band gap values with an increase in $x$ content in the $\left(\mathrm{Ba}_{1-x} \mathrm{Sr}_{x}\right) \mathrm{MoO}_{4}$ ceramics. PL emissions exhibit a non-linear behavior to increase or decrease with the increase of $\mathrm{Sr}^{2+}$ ions in the tetragonal lattices, when excited by a wavelength of $350 \mathrm{~nm}$. The $P-E$ decreases along with slim hysteresis loop towards higher $\mathrm{Sr}^{2+}$ ions concentration. These effects are correlated with decrease in lattice parameters and $c / a$ ratio in this tetragonal lattice. The microwave dielectric constant and quality factor were measured using the method proposed by Hakki-Coleman. Temperature coefficient and quality factor of these materials were measured by vector network analyzer.

\section{Introduction}

Recently, extensive research has been conducted on alkaline molybdate and tungstates materials because these materials have been widely employed in several industrial applications, such as: optoelectrical devices, microwave dielectric devices, gas sensor, photo-catalyst, amplifier and electrochromic devices [1-8]. These alkaline materials can be classified into two different classes; the first has a wolframite-type monoclinic structure and second has a scheelite-type tetragonal structure both with a general formula: $\mathrm{ABO}_{4}$, where: $\left(\mathrm{A}=\mathrm{Ba}^{2+}, \mathrm{Sr}^{2+}, \mathrm{Ca}^{2+}, \mathrm{Mg}^{2+}\right.$, $\mathrm{Zn}^{2+}$ and $\mathrm{Pb}^{2+}$ ions) and $\left(\mathrm{B}=\mathrm{Mo}^{6+}\right.$ and $\left.\mathrm{W}^{6+}\right)[9,10]$. Depending on the electronic density and size of $\mathrm{A}^{2+}$ ionic radius ions, the molybdates and tungstates can display one of two types of structure [11]. The larger $\mathrm{Ba}^{2+}$ and $\mathrm{Sr}^{2+}$ cations are coordinated to eight oxygen $(\mathrm{O})$ atoms in solid in tetragonal lattice which is composed of deltahedral 
$\left[\mathrm{BaO}_{8}\right] /\left[\mathrm{SrO}_{8}\right]$ clusters and tetrahedral $\left[\mathrm{MoO}_{4}\right]$ clusters, while the smaller $\mathrm{Mg}^{2+}$ and $\mathrm{Zn}^{2+}$ cations are coordinated to six $\mathrm{O}$ atoms in solid in tetragonal lattice which is composed both by octahedral $\left[\mathrm{MgO}_{6}\right] /\left[\mathrm{ZnO}_{6}\right]$ and $\left[\mathrm{MoO}_{6}\right]$ clusters $[12$, 13]. Moreover, in $\mathrm{AWO}_{4}$ and/or $\mathrm{AMoO}_{4}$ materials with scheelite-type tetragonal structure have a body centered tetragonal scheelite structure, with four formula units per primitive cell $(Z=4)$ [14]. These molybdates are good host materials for other alkaline and rare earth elements and have been used to improve many physical properties, such as: photoluminescence (PL), optical band gap, ferroelectric, dielectric, and photocatalysis [15-19]. These electronic properties are related to the presence of order-disorder and/ or distortion at medium range into tetragonal lattice [20]. Depending on the nature of the substituted ions into tetragonal lattice in the host matrix of scheelite materials enhances the intensity of PL spectra and shift towards the shorter wavelength region at room temperature [21, 22]. The existence of localized energy levels in between conduction and valence band has a significant effect on the values of the band gap [23]. The thermodynamics and enthalpies of formation of tungstates and molybdate materials depends on the ionic radii, $\mathrm{pH}$ and alkaline earth metals which is highest in $\mathrm{BaWO}_{4}$ and $\mathrm{BaMoO}_{4}$ compounds compare to other alkaline metals followed by strontium molybdate $\mathrm{SrMoO}_{4}(\mathrm{SMO})$, $\mathrm{CaMoO}_{4}(\mathrm{CMO})$ etc., its kinetics of formation governs the transport of matter during heating process [24-26]. Moreover, different synthesis method and heating process, such as: solid state reaction route [27-30], precipitation [31-34], hydrothermal conventional [35, [36], polymeric precursor method [37, 38], microwave-hydrothermal [39, 40] and micro-emulsion method $[41,42]$ has been used to prepared the $\mathrm{BaMoO}_{4}$ and $\mathrm{SrMoO}_{4}$ materials. It is being observed that these synthesis techniques are responsible for evolution for various morphological grains and hence changes the physical and chemical properties of these ceramics materials.

A few papers have been reported in literature for ostentation of $\left(\mathrm{Ba}_{1-x} \mathrm{Sr}_{x}\right) \mathrm{MoO}_{4}$ solution solids in form of thin films [43-45] and powders [46, 47]. Therefore, in this paper, we report on the effective way to improve the electronic properties of $\left(\mathrm{Ba}_{1-x} \mathrm{Sr}_{x}\right) \mathrm{MoO}_{4}$ ceramics synthesized by the solid state reactions. The difference in ionic sizes of the doping elements manifested itself the overall structure in the form of Goldschmidt's tolerance factor $(t)$ is found to be important parameters in controlling the microwave dielectric, ferroelectric hysteresis loop, switching of polarization, shifting of Raman active modes and bending and stretching of metal-oxide polyhedra bonds in micro-Raman spectra. For $t>1$, Mo-site has much room, resulting in increase of damping of the second mode involving the B-site vibration. Damping could be minimized by changing the ionic size to fulfill $\mathrm{t} \sim 1$. Based on this concept, we choose smaller sized $\mathrm{Sr}^{2+}$ ions in place of higher radii $\mathrm{Ba}^{2+}$ ions at $\mathrm{A}$-site so as to reduce the $t$ values. The physical properties of this scheelite materials are coupled with the unit cell dimension, crystal symmetry, as well the nature of the band structure. Finally, in work, we explain with more details their optical, microstructural, dielectric and ferroelectric properties.

\section{Experimental procedure}

\subsection{Synthesis of $\left(\mathrm{Ba}_{1-x} \mathrm{Sr}_{x}\right) \mathrm{MoO}_{4}$ ceramics}

The $\left(\mathrm{Ba}_{1-x} \mathrm{Sr}_{x}\right) \mathrm{MoO}_{4}$ ceramics with $(x=0 ; 0.1 ; 0.2,0.3$; $0.4 ; 0.5 ; 0.6 ; 0.7,0.8 ; 0.9$, and 1$)$ were prepared using solid state reaction method. High purity chemical barium carbonate $\left[\mathrm{BaCO}_{3}\right](99 \%$ Merck India Ltd.), strontium carbonate $\left[\mathrm{SrCO}_{3}\right](99 \%$, Himedia Chemicals) and molybdenum oxide $\left[\mathrm{MoO}_{3}\right]$ (99\%, Alfa Aesar) has been used. The stoichiometrically calculated reagents are thoroughly mixed in the liquid medium using agate mortar and pestle for $6 \mathrm{~h}$. Then the dried ceramics at different $(x)$ compositions were heat treated at $850{ }^{\circ} \mathrm{C}$ for $4 \mathrm{~h}$ and $1000{ }^{\circ} \mathrm{C}$ for $2 \mathrm{~h}$ with intermediate grinding. The solid solution reaction occurs according to Eq. (1) below:

$$
\begin{aligned}
& (1-x) \mathrm{BaCO}_{3(\mathrm{~s})}+1 \mathrm{MoO}_{3(\mathrm{~s})}+(x) \mathrm{SrCO}_{3(\mathrm{~s})} \\
& \quad \rightarrow\left(\mathrm{Ba}_{1-x} \mathrm{Sr}_{x}\right) \mathrm{MoO}_{4(\mathrm{~s})}+2 \mathrm{CO}_{2(\mathrm{~g})}
\end{aligned}
$$

These ceramics were structurally characterized as presented in the following section.

\subsection{Characterizations}

Structural characterization of all these ceramics were done by X-ray diffractions (XRD) patterns using a Philips diffractometer model $\mathrm{PW}-1830$ with $\mathrm{Cu}-\mathrm{K} \alpha$ radiation $(\lambda=1.5406 \AA)$ in the $2 \theta$ range from $20^{\circ}$ to $75^{\circ}$ in the normal routine with a scanning velocity of $0.02^{\circ}$ and from $20^{\circ}$ to $80^{\circ}$ with a scanning velocity of $1 \% \mathrm{~min}$ in the Rietveld routine (both with $4 \mathrm{~h}$ of measurement). The samples calcined at $1000{ }^{\circ} \mathrm{C}$ and above showed single phase character without any evidence of any secondary phase. Thus, $1000{ }^{\circ} \mathrm{C}$ is considered as the optimized calcinations temperature for all the compositions. The calcined monophasic molybdate powder was mixed with polyvinyl alcohol as a binder and pressed uniaxially under pressure of $80 \mathrm{~kg} / \mathrm{cm}^{2}$ to form disk shape pellet of $10 \mathrm{~mm}$ diameter and $1.5 \mathrm{~mm}$ thickness. These pellets were sintered at $1050{ }^{\circ} \mathrm{C}$ for $2 \mathrm{~h}$ to provide maximum shrinkage and compactness. Structural refinement was carried out for all the compositions $x=0.00-0.10$ using the Rietveld's refinement program EXPGUI interface to the program GSAS (General Structural Analysis System). Raman 
spectroscopic studies were done by using (in Via, Reishaw, UK) an excitation wavelength of $514 \mathrm{~nm}$. The Fourier transform infra red (FTIR) spectra were recorded at room temperature by the standard $\mathrm{KBr}$ pellet technique using a FTIR Spectrophotometer (Spectrum 1000, Perkin Elmer, Japan). The diffuse reflectance spectra of the pure and doped ceramics powder samples was taken at room temperature using double beam UV-Visible spectrometer (Lambda 35, Winlab V6.0, Perkin-Elmer, USA). PL measurements were made with a Monospec 27 monochromator (Thermal Jarrel Ash, USA) coupled to an R446 photomultiplier (Hamamatsu Photonics, Japan). A krypton ion laser (Coherent Innova 90K, USA) $(\lambda=350 \mathrm{~nm})$ was used as the excitation source; its maximum output power was maintained at $500 \mathrm{~mW}$. Microstructure characterization was performed using a scanning electron microscope (SEM, JEOL-6330F, JEOL, Japan). Room temperature dielectric constant and dielectric loss were measure by using Alpha high resolution dielectric impedance analyzer (Novacontrol, Gmbh, Germany) at a frequency range $1 \mathrm{~Hz}-1 \mathrm{GHz}$. That especially optimized for dielectric materials with low loss factor over a broad frequency range. Before conducting any impedance measurements a calibration was carried out using an internal calibration. Ferroelectric hysteresis loop and switching polarization were measured on $10 \mathrm{~mm}$ diameter and $1.5 \mathrm{~mm}$ thickness silver coated samples at different applied voltage using precision high voltage amplifier interface (Radiant Tec. Inc., Model no. HVA 100611-792, USA). Microwave dielectric measurement are performed by using a Vector Network Analyzer (N5230A, Agilent Technologies, USA) in a $\mathrm{TE}_{01 \delta}$ mode of cylindrical shaped of $\mathrm{BaMoO}_{4}$, $\left(\mathrm{Ba}_{1-x} \mathrm{Sr}_{x}\right) \mathrm{MoO}_{4}$ and $\mathrm{SrMoO}_{4}$ materials.

\section{Results and discussion}

\subsection{XRD analyses}

Figure 1a, b illustrates the XRD pattern of $\left(\mathrm{Ba}_{1-x} \mathrm{Sr}_{x}\right)$ $\mathrm{MoO}_{4}$ ceramics from $(x=0$ to 0.5$)$ and from $(x=0.6$ to 1) heat treated at $1000{ }^{\circ} \mathrm{C}$ for $2 \mathrm{~h}$, respectively.

All diffraction peaks indicate that $\left(\mathrm{Ba}_{1-x} \mathrm{Sr}_{x}\right) \mathrm{MoO}_{4}$ ceramics with different composition are monophasic nature indexed to the scheelite-type tetragonal structure with space group $\mathrm{I}_{1} / \mathrm{a}$, which is in agreement with the inorganic crystal structure database (ICSD) card No. 50281 for $\mathrm{BaMoO}_{4}$ and 173120 for $\mathrm{SrMoO}_{4}$ and, respectively $[48,49]$. The sharp and well defined diffraction peaks indicated a high degree of crystallinity and structurally long range ordered system. The diffraction peaks are found shifted to higher $2 \theta$ position with an increase of $\mathrm{Sr}^{2+}$ ion concentration. According to the
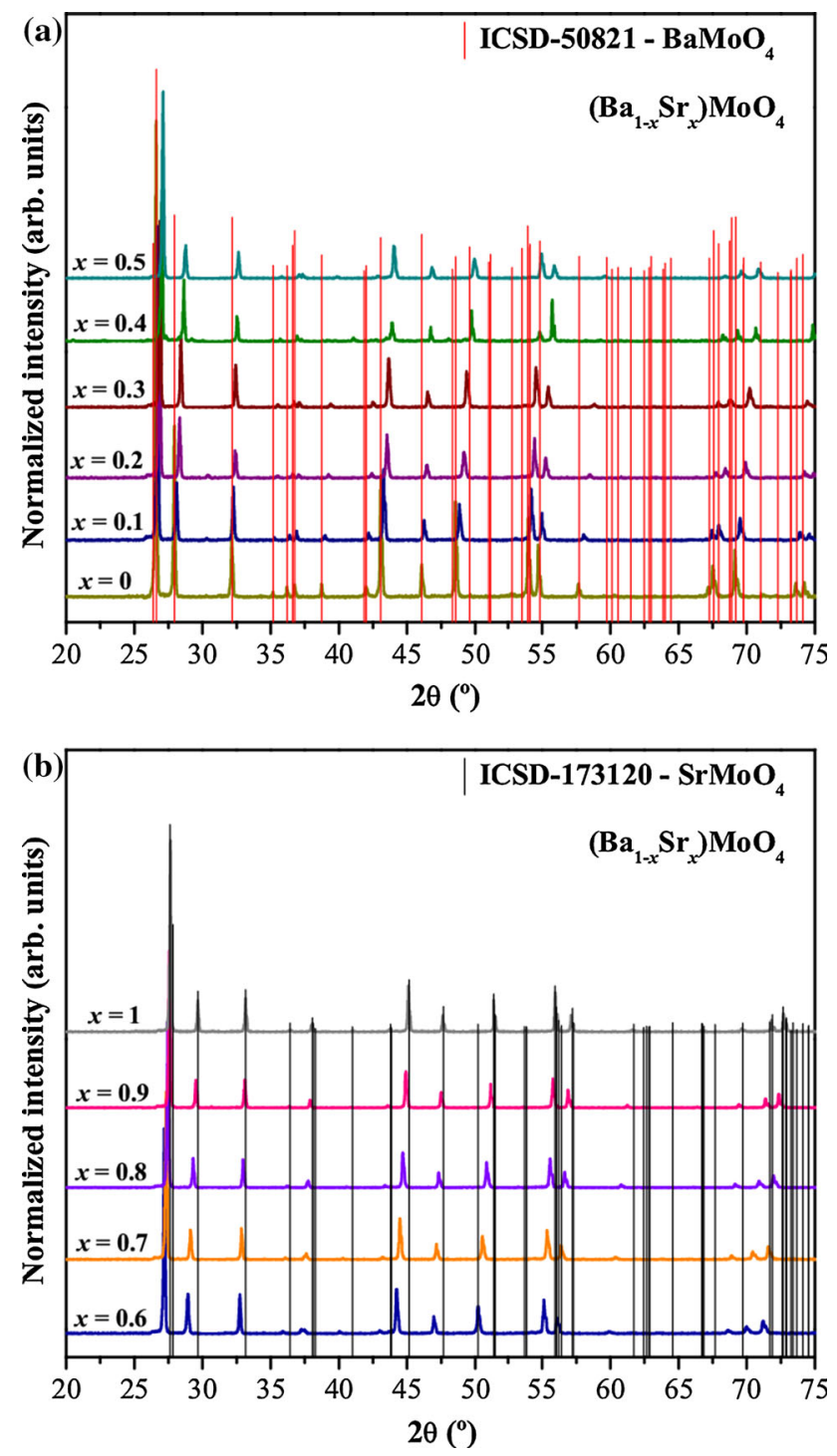

Fig. 1 XRD patterns of $\left(\mathrm{Ba}_{1-x} \mathrm{Sr}_{x}\right) \mathrm{MoO}_{4}$ ceramics with $x$ in the range from a 0 to 0.5 and $\mathbf{b} 0.6$ to 1 heat treated at $1000{ }^{\circ} \mathrm{C}$. The vertical lines indicate the position and relative intensity of the ICSD card No. 50821 and No. 173120 for $\mathrm{BaMoO}_{4}$ and $\mathrm{SrMoO}_{4}$ phases, respectively

Bragg's law $(\lambda=2 \mathrm{~d} \sin \theta)$ this shift of $2 \theta$ position occur when there is a reduction in unit cell lattice parameters and hence decrease in cell volume.

\subsection{Rietveld refinements analyses}

Rietveld refinement program [50] has been used to calculate the lattice parameters with the structural refinement plots as shown Fig. 2a-f for some $(x)$ compositions of $\left(\mathrm{Ba}_{1-x} \mathrm{Sr}_{x}\right) \mathrm{MoO}_{4}$ ceramics forming solution solids.

The background was modeled by 16 terms linear interpolation function. The peak profile were described by a pseudo-Voigt function, profile half-width parameters $(u, v$, 

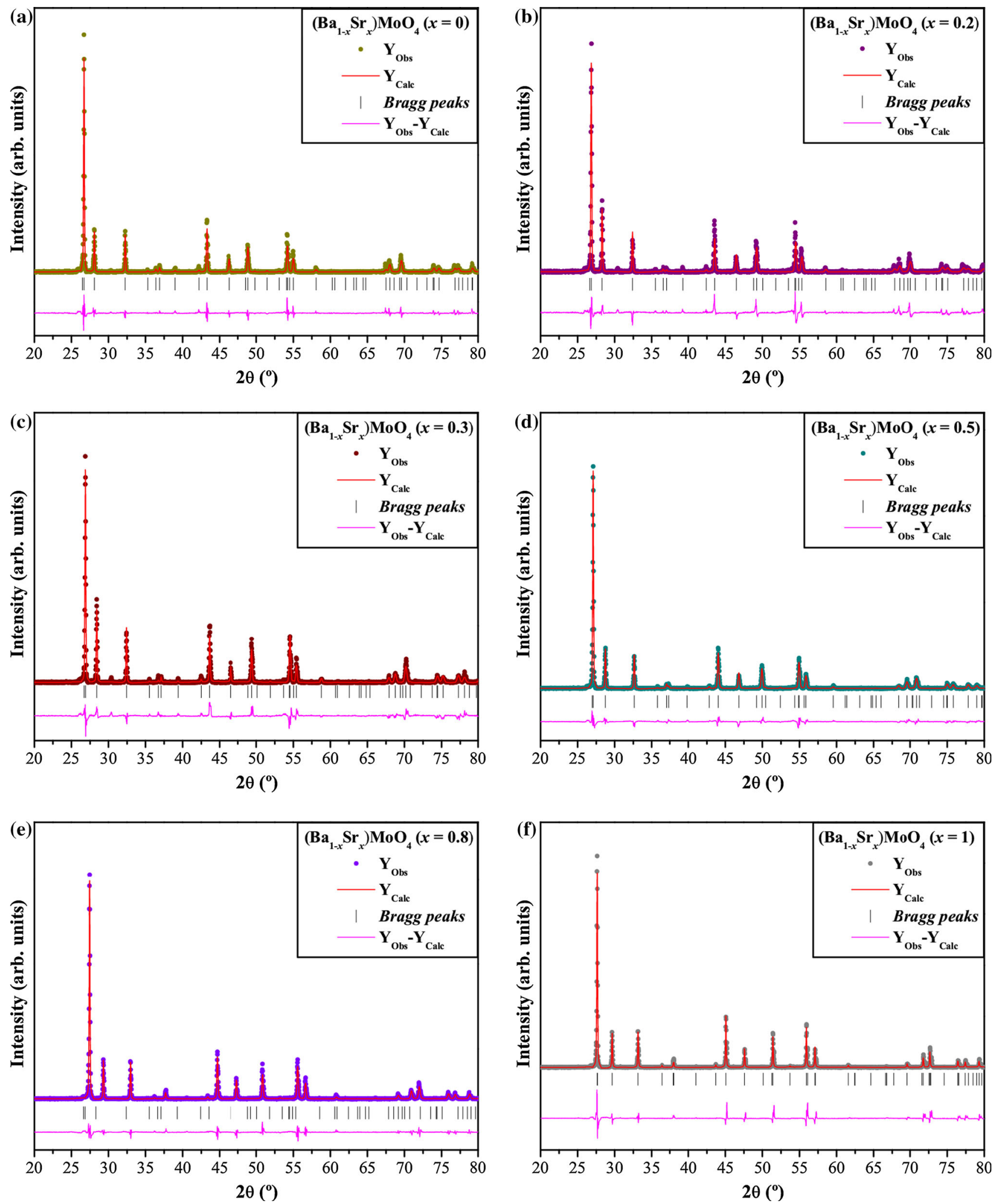

Fig. 2 Rietveld refinement plots of selected $\left(\mathrm{Ba}_{1-x} \mathrm{Sr}_{x}\right) \mathrm{MoO}_{4}$ ceramics for some concentrations with: a $x=0, \mathbf{b} x=0.2$, c $x=0.3$, d $x=0.5$, e $x=0.8$, and $\mathbf{f} x=1$ 
$w$ ), isotopic displacement parameters, preferred orientation factor, occupancy and atomic functional position, Lorentzian peak broadening factor, and microstrain effect of crystallites where subsequently refined. The structural refinement was performed between the experimental and observed XRD pattern and yields acceptable reliable factor. Details regarding the Rietveld refinements are listed in Table 1.

In Table 1 are presents the Rietveld refinement data for $\left(\mathrm{Ba}_{1-x} \mathrm{Sr}_{x}\right) \mathrm{MoO}_{4}$ ceramics at different $(x)$ compositions. Some variation in the atomic position of oxygen's atoms was observed, while barium, strontium and molybdenum atoms have fixed atomic position (Table 1). Hence these variations in the atomic positions of the oxygen's atoms can leads to the formation of different types of distortions in $(\mathrm{O}-\mathrm{Ba}-\mathrm{O}),(\mathrm{O}-\mathrm{Sr}-\mathrm{O})$, and $(\mathrm{O}-\mathrm{Mo}-\mathrm{O})$ bonds and subsequently produce different levels of distortion in deltahedral $\left[\mathrm{BaO}_{8}\right] /\left[\mathrm{SrO}_{8}\right]$ clusters and tetrahedral $\left[\mathrm{MoO}_{4}\right]$ clusters in the lattice [51].

\subsection{Lattice parameters and unit-cell volume analyses}

The substitution of $\mathrm{Sr}^{2+}$ ions at A-site reduces the lattice parameter and unit cell volume of $\left(\mathrm{Ba}_{1-x} \mathrm{Sr}_{x}\right) \mathrm{MoO}_{4}$ ceramics as illustrated in Fig. 3 and inset Fig. 3, respectively.

A subsequent lattice strain has been observed due to $\mathrm{Sr}^{2+}$ ion substitution in the host lattice. This strain generated when two adjacent grain come in contact during their growth. Induce lattice strain is calculated by using the relation in Eq. (2):

$s=\frac{\Delta d}{d}=\frac{d_{d}-d_{p}}{d_{p}}$

where, $d_{d}$ and $d_{p}$ are lattice spacing of substituted $\left(\mathrm{Ba}_{1-x}\right.$ $\left.\mathrm{Sr}_{x}\right) \mathrm{MoO}_{4}$ ceramics and pure $\mathrm{BaMoO}_{4}$ ceramics, respectively. When $d_{d}<d_{p}$, strain is negative suggesting the

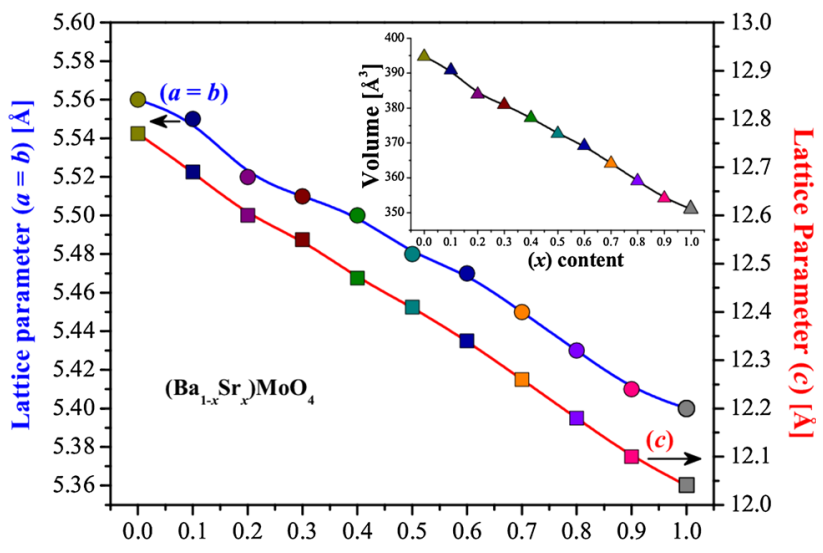

(x) content

Fig. 3 Change in lattice parameters $(a=b \neq c)[\AA]$ and (inset) unit cell volume $(a \times b \times c)\left[\AA^{3}\right]$ for $\left(\mathrm{Ba}_{1-x} \mathrm{Sr}_{x}\right) \mathrm{MoO}_{4}$ ceramics with different $x$ concentrations

compressive strain in the materials were listed in Table 1. The values of compressive strain increased with $\mathrm{Sr}^{2+}$ ions concentration, which indicated the higher diffusion and kinetics of $\mathrm{Sr}^{2+}$ ions in matrix host $\mathrm{BaMoO}_{4}$ lattice. In addition, the average grain size is also calculated by using the Scherrer's formulae: $D=\frac{0.9 \lambda}{B \cos \theta_{B}}$ where, $D$ is the grain size, $\lambda$ is the $\mathrm{X}$-ray wavelength, $B$ is full width half maxima (FWHM) at peak position $26.5^{\circ}(112)$ and $\theta_{B}$ is the Bragg's diffraction angle [52].

\subsection{Representation of the $\mathrm{BaMoO}_{4}$, $\left(\mathrm{Ba}_{0.5} \mathrm{Sr}_{0.5}\right) \mathrm{MoO}_{4}$ and $\mathrm{SrMoO}_{4}$ unit cells}

Figure $4 \mathrm{a}-\mathrm{c}$ illustrate the schematic representation of unit cell tetragonal structure for a selected concentration of $\left(\mathrm{Ba}_{1-x} \mathrm{Sr}_{x}\right) \mathrm{MoO}_{4}$ ceramics with $(x=0,0.5$ and 1$)$.

Standardization of crystal structure and fractional coordinate was modeled by visualization for electronic and
Table 1 Lattice parameters, unit cell volume, statistical parameters of quality obtained by Rietveld refinement and strain lattice for the $\left(\mathrm{Ba}_{1-x} \mathrm{Sr}_{x}\right) \mathrm{MoO}_{4}$ ceramics at different $x$ concentration synthesized by solid state method

\begin{tabular}{llllllll}
\hline$\left(\mathrm{Ba}_{1-x} \mathrm{Sr}_{x}\right) \mathrm{MoO}_{4}$ & \multicolumn{2}{l}{ Lattice parameters $(\AA)$} & Unit cell volume $\left(\AA^{3}\right)$ & $R_{w p}$ & $R_{p}$ & $\chi^{2}$ & $S$ \\
\cline { 2 - 6 } & $a=b$ & $c$ & & & & & \\
\hline$x=0$ & 5.56 & 12.77 & 395.41 & 0.340 & 0.267 & 1.22 & - \\
$x=0.1$ & 5.55 & 12.69 & 390.88 & 0.031 & 0.017 & 1.82 & -0.004 \\
$x=0.2$ & 5.52 & 12.60 & 383.92 & 0.018 & 0.009 & 2.10 & -0.008 \\
$x=0.3$ & 5.51 & 12.55 & 381.01 & 0.016 & 0.008 & 1.95 & -0.009 \\
$x=0.4$ & 5.50 & 12.47 & 377.21 & 0.010 & 0.006 & 1.66 & -0.014 \\
$x=0.5$ & 5.48 & 12.41 & 372.76 & 0.005 & 0.002 & 2.50 & -0.016 \\
$x=0.6$ & 5.47 & 12.34 & 364.15 & 0.002 & 0.001 & 2.00 & -0.020 \\
$x=0.7$ & 5.45 & 12.26 & 364.15 & 0.005 & 0.004 & 1.25 & -0.024 \\
$x=0.8$ & 5.43 & 12.18 & 359.12 & 0.006 & 0.003 & 2.00 & -0.028 \\
$x=0.9$ & 5.41 & 12.10 & 354.14 & 0.007 & 0.003 & 2.33 & -0.031 \\
$x=1$ & 5.40 & 12.04 & 351.08 & 0.013 & 0.004 & 2.71 & -0.033 \\
\hline
\end{tabular}




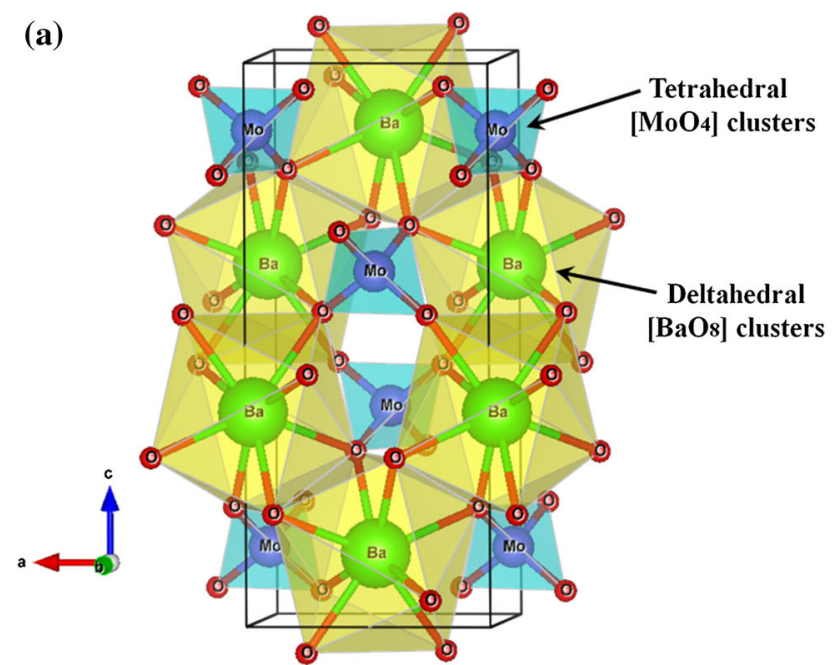

(b)

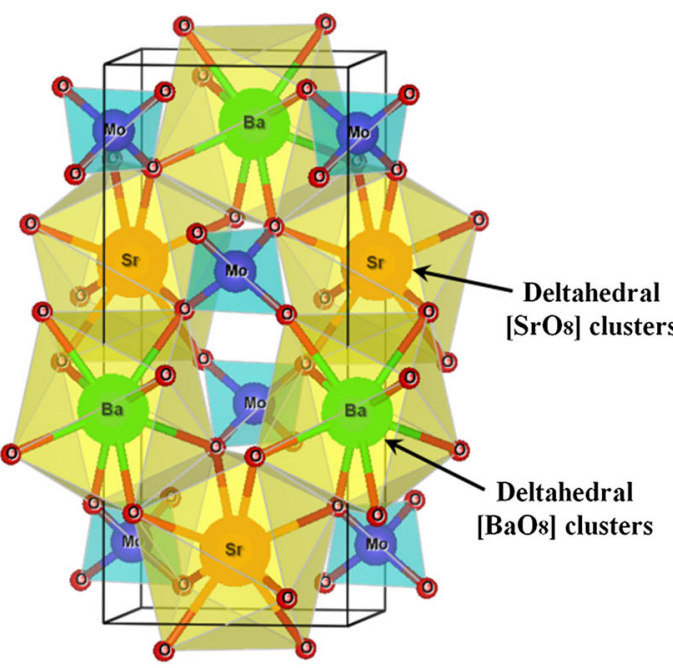

(c)

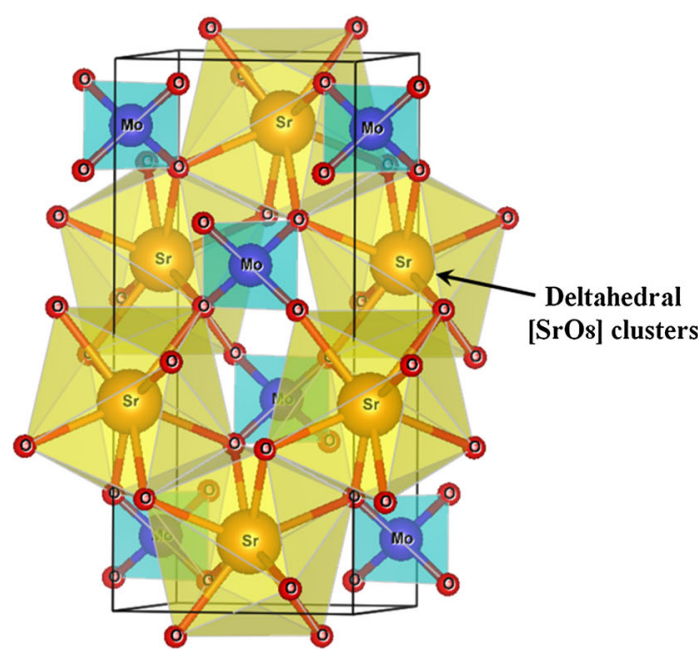

Fig. 4 Schematic representation of tetragonal $\left(\mathrm{Ba}_{1-x} \mathrm{Sr}_{x}\right) \mathrm{MoO}_{4}$ unit cells with $\left[\mathrm{BaO}_{8}\right]-\left[\mathrm{SrO}_{8}\right]-\left[\mathrm{MoO}_{4}\right]$ clusters for some concentrations with: $\mathbf{a} x=0, \mathbf{b} x=0.5$, and $\mathbf{c} x=1$, respectively structural analysis (VESTA) program version 3.2.1 [53, 54] using the lattice parameters and atomic coordinate obtained from Rietveld refinement data presented in Tables 1 and 2.

In Table 2 the as it can be to observe some variations in the atomic positions related to oxygen atoms were observed, while the barium, strontium and molybdenum atoms have fixed atomic positions. These results indicate that the positions of the oxygen atoms are very variable in the lattice as shown by the X-ray powder diffraction data technique. In Fig. 4a-c, these unit cells, all the molybdenum atoms are coordination by four oxygen atoms which form tetraedral $\left[\mathrm{MoO}_{4}\right]$ cluster with a symmetry group $T_{d}$ and tetrahedron polyhedra. These tetrahedral clusters were slightly distorted in matrix $\left(\mathrm{Ba}_{1-x} \mathrm{Sr}_{x}\right) \mathrm{MoO}_{4}$ lattice as a result this distortion in tetrahedral $\left[\mathrm{MoO}_{4}\right]$ clusters cause changes in $\mathrm{O}-\mathrm{Mo}-\mathrm{O}$ bond length and bond angle which further modified the energy levels and enhanced structural order-disorder in the host lattice [55]. On the other hand barium and strontium atoms are bonded to eight oxygen atoms and formed deltahedral $\left[\mathrm{BaO}_{8}\right] /\left[\mathrm{SrO}_{8}\right]$ clusters with a symmetry group of $\left(D_{2 d}\right)$. The deltahedral $\left[\mathrm{BaO}_{8}\right]$ clusters have the same coordination number as the deltahedral $\left[\mathrm{SrO}_{8}\right]$ clusters in A-site and only different electronic environment which influence the optical and electrical properties in the material [56].

\subsection{Micro-Raman spectroscopy analyses}

According to the group theory calculation, molybdate with a scheelite-type tetragonal structure contain 26 different vibration modes which are as follows Eq. (3) below [57]:

$$
\begin{aligned}
\Gamma_{\{(\text {Raman })+[\text { Infrared }]\}=} & \left(3 \mathrm{~A}_{\mathrm{g}}+5 \mathrm{~B}_{\mathrm{g}}+5 \mathrm{E}_{\mathrm{g}}\right) \\
& +\left[5 \mathrm{~A}_{\mathrm{u}}+3 \mathrm{~B}_{\mathrm{u}}+5 \mathrm{E}_{\mathrm{u}}\right]
\end{aligned}
$$

where, $A_{g}, B_{g}$, and $E_{g}$ are Raman active vibrational modes. The $A$ and $B$ modes are non-degenerate, whereas the $E$ modes are doubly degenerate. $A_{g}, B_{g}$ and $\mathrm{E}_{\mathrm{g}}$ are Raman modes that arise from the same motion of clusters in the $\left(\mathrm{Ba}_{1-x} \mathrm{Sr}_{x}\right) \mathrm{MoO}_{4}$ lattice. Therefore, 13 Raman-active vibrational modes in $\left(\mathrm{Ba}_{1-x} \mathrm{Sr}_{x}\right) \mathrm{MoO}_{4}$ materials are anticipated according to Eq. (4) below [58]:

$\Gamma_{\{(\text {Raman }\}}=\left(3 \mathrm{~A}_{\mathrm{g}}+5 \mathrm{~B}_{\mathrm{g}}+5 \mathrm{E}_{\mathrm{g}}\right)$

Vibration modes observed in Raman spectra for molybdate are further classified into two groups: internal and external vibrational modes. The internal vibrational modes are related to $\left[\mathrm{MoO}_{4}\right]$ tetrahedral clusters vibration in the lattice. The external modes are related to phonon lattice vibration which correspond to $\left[\mathrm{BaO}_{8}\right] /\left[\mathrm{SrO}_{8}\right]$ deltahedral clusters [47]. In isolated tetrahedral $\left[\mathrm{MoO}_{4}\right]$ have a cubic symmetry $\left(T_{d}\right)$ and their vibration consist of 
Table 2 Atomic coordinates $(x, y, z)$ obtained by Rietveld refinement for selected $x$ concentration of $\left(\mathrm{Ba}_{1-x} \mathrm{Sr}_{x}\right) \mathrm{MoO}_{4}$ ceramics materials

\begin{tabular}{lllllll}
\hline Atoms & \multicolumn{2}{l}{$\left(\mathrm{Ba}_{1-x} \mathrm{Sr}_{x}\right) \mathrm{MoO}_{4}$} & & \\
\cline { 2 - 6 } Atomic positions & $x=0$ & $x=0.2$ & $x=0.4$ & $x=0.6$ & $x=0.8$ & $x=1$ \\
\hline $\mathrm{Ba}$ & & & & & \\
$(x)$ & 0 & 0 & 0 & 0 & 0 & 0 \\
$(y)$ & 0.25 & 0.25 & 0.25 & 0.25 & 0.25 & 0.25 \\
$(z)$ & 0.65 & 0.65 & 0.65 & 0.65 & 0.65 & 0.65 \\
$\mathrm{Sr}$ & & & & & \\
$(x)$ & 0 & 0 & 0 & 0 & 0 & 0 \\
$(y)$ & 0.25 & 0.25 & 0.25 & 0.25 & 0.25 & 0.25 \\
$(z)$ & 0.65 & 0.65 & 0.65 & 0.65 & 0.65 & 0.65 \\
$\mathrm{Mo}$ & & & & & \\
$(x)$ & 0 & 0 & 0 & 0 & 0 & 0 \\
$(y)$ & 0.25 & 0.25 & 0.25 & 0.25 & 0.25 & 0.25 \\
$(z)$ & 0.12 & 0.12 & 0.12 & 0.12 & 0.12 & 0.12 \\
$\mathrm{O}$ & & & & & \\
$(x)$ & 0.228 & 0.236 & 0.226 & 0.248 & 0.234 & 0.246 \\
$(y)$ & 0.135 & 0.389 & 0.396 & 0.378 & 0.392 & 0.365 \\
$(z)$ & 0.049 & 0.159 & 0.191 & 0.190 & 0.193 & 0.194 \\
\hline
\end{tabular}

four internal modes such as: $v_{1}\left(A_{1}\right), v_{2}(E), v_{3}\left(F_{2}\right), v_{4}\left(F_{2}\right)$, one free rotational $v_{f . r}\left(F_{1}\right)$ modes and one external $v_{\text {ext }}\left(F_{2}\right)$ modes [59]. In scheelite-type tetragonal symmetry $\left[\mathrm{MoO}_{4}\right]$ clusters is reduced to $\mathrm{S}_{4}$ point symmetry.

Figure 5a, b show of $\left(\mathrm{Ba}_{1-x} \mathrm{Sr}_{x}\right) \mathrm{MoO}_{4}$ ceramics from $(x=0$ to 0.5$)$ and from $(x=0.6$ to 1$)$ heat treated at $1000{ }^{\circ} \mathrm{C}$ for $2 \mathrm{~h}$, respectively.

In order to better understand, the region between 100 and $950 \mathrm{~cm}^{-1}$ was highlighted and ten different vibration modes were identified. The internal modes $v_{1}\left(A_{1}\right), v_{2}(E), v_{3}$ $\left(F_{2}\right), v_{4}\left(F_{2}\right)$, were observed in the range between 888 to $892 \mathrm{~cm}^{-1}, 846$ to $839 \mathrm{~cm}^{-1}, 797$ to $791 \mathrm{~cm}^{-1}, 383$ to $360 \mathrm{~cm}^{-1}, 368$ to $347 \mathrm{~cm}^{-1}$, and 331 to $325 \mathrm{~cm}^{-1}$. The free rotational mode $v_{f . r}\left(F_{1}\right)$ was detected in range between 184 and $192 \mathrm{~cm}^{-1}$ and external $v_{\text {ext }}\left(F_{2}\right)$ modes were detected in between 108 and $139 \mathrm{~cm}^{-1}$ frequency range. The results are in agreement with that reported in the previous literature [60]. The Raman spectra vibrational modes are related to $(\leftarrow \mathrm{O}-\mathrm{Mo}-\mathrm{O} \rightarrow)$ symmetry stretching of tetrahedral $\left[\mathrm{MoO}_{4}\right]$ clusters assigned as $v_{1}\left(A_{1}\right)$, symmetry bending vibration $v_{2}(E)$, anti-symmetry stretching $v_{3}$ $\left(F_{2}\right)$, anti-symmetry bending vibration $v_{4}\left(F_{2}\right)$ and free rotational $v_{f . r}\left(F_{1}\right)$ mode. The external modes $v_{\text {ext }}$ are correspond to the motion of the deltahedral $\left[\mathrm{BaO}_{8}\right] /\left[\mathrm{SrO}_{8}\right]$ clusters assigned as a symmetry bending. It is observed that an increase in $\mathrm{Sr}^{2+}$ ions concentration in host matrix induced a shift in Raman active mode towards higher frequency side. These shifts in Raman modes are depend on the cationic mass of $\mathrm{AMoO}_{4}$ scheelite-type structure [61]. In $\left(\mathrm{Ba}_{1-x} \mathrm{Sr}_{x}\right) \mathrm{MoO}_{4}$ ceramics the mode frequency increased with a mass reduction of $\mathrm{A}^{2+}$ cation, i.e., substitution of
$\mathrm{Sr}^{2+}$ for $\mathrm{Ba}^{2+}$ cations. This behavior is probably due to lighter metal ion which strongly interacts with cluster group $\left[\mathrm{MoO}_{4}\right]$ and produces higher force constant and increase the vibrational frequency in $\left.\mathrm{Ba}_{1-x} \mathrm{Sr}_{x}\right) \mathrm{MoO}_{4}$ ceramics. The electronegativity of $\mathrm{Ba}^{2+}$ ions is different from $\mathrm{Sr}^{2+}$ ions and might be another factor which influences the shift in Raman active modes. The increase in electro negativity in $\mathrm{Sr}^{2+}$ cation results in higher force constant of the stretching vibration between tetrahedral $\left[\mathrm{MoO}_{4}\right]$ and deltahedral $\left[\mathrm{BaO}_{8}\right] /\left[\mathrm{SrO}_{8}\right]$ clusters and their respective [O-Ba-O-Mo-O-Ba-O], [O-Sr-O-Mo-O-Ba$\mathrm{O}]$ and [O-Sr-O-Mo-O-Sr-O] bond strength. As already mentioned earlier, the Rietveld refinement data indicated that the lattice parameters and unit cell volume decrease with the increase in $\mathrm{Sr}^{2+}$ ions concentration which indicated the reduction of $\mathrm{O}-\mathrm{Mo}-\mathrm{O}, \mathrm{O}-\mathrm{Ba}-\mathrm{O}$ and $\mathrm{O}-\mathrm{Sr}-\mathrm{O}$ bond lengths, is one of the reason to increase the force constant and vibrational frequency in these metallic groups. In addition, other factors which also influence the Raman active behavior, such as: average grain size, different methods of sample preparation and order-disorder correlation in host lattice.

\subsection{UV-Vis absorption spectroscopy and optical band gap values analyses}

The diffuse reflectance spectra (DR spectra) of the $\left(\mathrm{Ba}_{1-x} \mathrm{Sr}_{x}\right) \mathrm{MoO}_{4}$ ceramics in the range of $200-800 \mathrm{~nm}$ (UV-Vis) diffuse reflectance spectra are shown in Fig. 6a-f and the found optical band values for $\left[\left(\mathrm{Ba}_{1-x} \mathrm{Sr}_{x}\right) \mathrm{MoO}_{4}\right]$ ceramics with different $(x)$ contents are shown in Fig. $6 \mathrm{~g}$. 

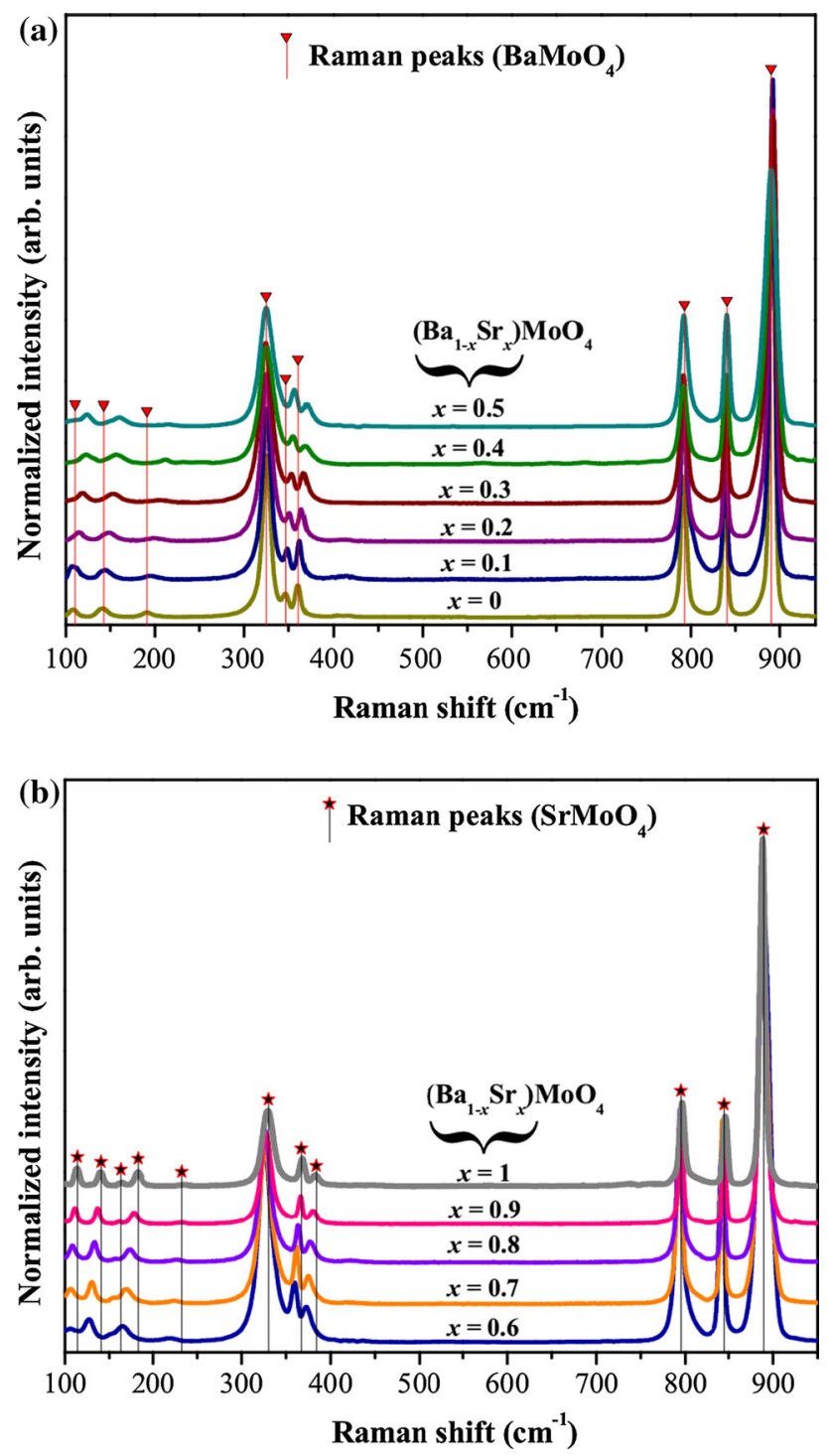

Fig. 5 Micro-Raman spectra of $\left(\mathrm{Ba}_{1-x} \mathrm{Sr}_{x}\right) \mathrm{MoO}_{4}$ ceramics with $x$ in the range from a 0 to 0.5 and $\mathbf{b} 0.6$ to 1 heat treated at $1000{ }^{\circ} \mathrm{C}$. The vertical lines indicate the position and relative intensity of down pointing triangle for $\mathrm{BaMoO}_{4}$ and asterisk $\mathrm{SrMoO}_{4}$ phases, respectively

The optical band gap energy $\left(E_{\text {gap }}\right)$ was calculated using the method proposed by Kubelka and Munk [62]. This methodology is based on the transformation of diffuse reflectance measurements to estimate $E_{g a p}$ values with good accuracy within the limits of the assumptions when modeled in three dimensions [63]. Particularly, it is useful in limited cases with an infinitely thick sample layer. The Kubelka-Munk Eq. (5) for any wavelength is described as:

$F\left(R_{\infty}\right) \equiv \frac{\left(1-R_{\infty}\right)^{2}}{2 R_{\infty}}=\frac{k}{s}$

where $F\left(R_{\infty}\right)$ is the Kubelka-Munk function or absolute reflectance of the sample. In our case, magnesium oxide
Fig. 6 UV-Vis diffuse reflectance spectra of the ceramics for some concentrations with: $\mathbf{a} x=0, \mathbf{b} x=0.2$, c $x=0.3$, d $x=0.5$, e $x=0.8$, and $\mathbf{f} x=1$ optical band gap values as a function of the $x$ concentration

$(\mathrm{MgO})$ was the standard sample used in reflectance measurements. $R_{\infty}=R_{\text {sample }} / R_{M g O}$, where $R_{\infty}$ is the reflectance when the sample is infinitely thick, $k$ is the molar absorption coefficient, and $s$ is the scattering coefficient. In a parabolic band structure, the optical band gap and absorption coefficient of semiconductor oxides [64] can be calculated using the following Eq. (6):

$\alpha h v=C_{1}\left(h v-E_{g a p}\right)^{n}$

where $\alpha$ is the linear absorption coefficient of the material, $h v$ is the photon energy, $C_{1}$ is a proportionality constant, and $n$ is a constant associated with the type of electronic transitions $(n=0.5,2,1.5$, and 3 for direct allowed, indirect allowed, direct forbidden, and indirect forbidden transitions, respectively). Finally, using the remission function described in Eq. (5) with the term $k=2 \alpha$ and $C_{2}$ as a proportionality constant, we obtain the modified Kubelka-Munk equation, as indicated in Eq. (7):

$\left[F\left(R_{\infty}\right) h v\right]^{2}=C_{2}\left(h v-E_{\text {gap }}\right)$

By finding the $F\left(R_{\infty}\right)$ value from Eq. (7) and plotting $\left[F\left(R_{\infty}\right) h v\right]^{2}$ against $h v$, the $E_{\text {gap }}$ value of the $\left[\left(\mathrm{Ba}_{1-x} \mathrm{Sr}_{x}\right)\right.$ $\left.\mathrm{MoO}_{4}\right]$ ceramics was determined. In the earlier literature $[51,65,66]$, it was established that $\mathrm{BaMoO}_{4}$ and $\mathrm{SrMoO}_{4}$ exhibit optical absorption spectra governed by direct transition between valence bands (VB) and conduction bands (CB). This characterization is observed when the electrons at the maximum of valence band transit to minimum of conduction band at the same point in the Brillouin zone [67]. Molybdenum atoms in general present an ideal position at tetrahedron center forming tetrahedral $\left[\mathrm{MoO}_{4}\right]$ clusters. However, our $\left[\left(\mathrm{Ba}_{1-x} \mathrm{Sr}_{x}\right) \mathrm{MoO}_{4}\right]$ ceramics were prepared by the solid state reactions and the successive milling cycles can provoke several distortions or simultaneous presence of order-disorder into the lattice. These effects can cause small displacements of Mo atoms ofcenter of symmetry center tetrahedral $\left[\mathrm{MoO}_{4}\right]$ clusters [68]. These local disorder effect increase the defects between the $\left[\mathrm{BaO}_{8}\right]-\left[\mathrm{MoO}_{4}\right]-\left[\mathrm{BaO}_{8}\right], \quad\left[\mathrm{BaO}_{8}\right]-\left[\mathrm{MoO}_{4}\right]-\left[\mathrm{SrO}_{8}\right]$ and $\left[\mathrm{SrO}_{8}\right]-\left[\mathrm{MoO}_{4}\right]-\left[\mathrm{SrO}_{8}\right]$ clusters as shown previous in Fig. $4 \mathrm{a}-\mathrm{c}$, which generate new electronic energy levels within the band gap $[69,70]$, reducing the optical band gap as illustrated in Fig. 6a-f. Therefore, the decrease in the band gap values $\left(E_{\text {gap }}\right)$ values with increase in $\mathrm{Sr}^{2+}$ ions concentration are attributed to increase in local lattice distortions and intermediary energy levels within band gap and decrease of local electronic density as indicated in the Fig. 6g. 

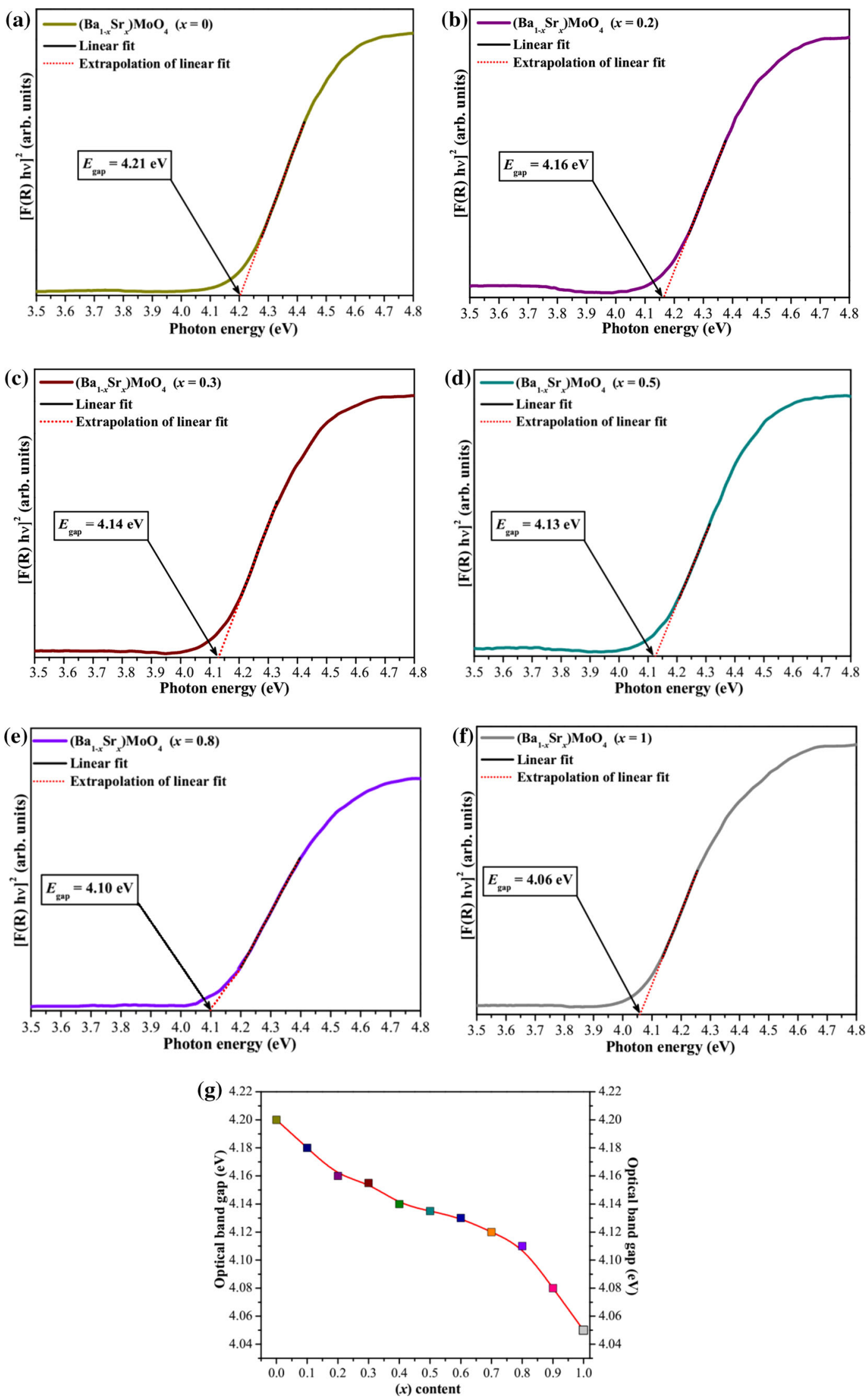


\subsection{PL emission analyses}

The photoluminescence spectra at room temperature for $\left(\mathrm{Ba}_{1-x} \mathrm{Sr}_{x}\right) \mathrm{MoO}_{4}$ ceramics at different $(x)$ concentrations heat treated at $1000{ }^{\circ} \mathrm{C}$ for $2 \mathrm{~h}$ are shown in Fig. 7 .

The scheelite molybdate compounds are well known for exhibit very good emission luminescence at low and at room temperature [71-78]. The spectrum cover a wide band of range from 400 to $700 \mathrm{~nm}$ wavelength of the visible spectra, and the profile of the emission band is typically involvement of multi-phonons and multi-levels process [79]. These levels are related to the numerous kind of defects directly related to degree of structural orderdisorder in the system. Several theories and explanation related to promote the emission spectra in barium and strontium molybdate based materials [80-82]. A possible explanation to shift of PL emission spectra can be related to modification on morphology/shape of the grains, JohnTeller splitting effect on the $\left[\mathrm{MoO}_{4}\right]$ tetrahedron, structural defects, charge transfer phenomena between $\left[\mathrm{MoO}_{4}\right]_{0}-$ $\left[\mathrm{MoO}_{4}\right]_{\mathrm{d}}$ complex clusters and surface defect at medium range [10, 83]. According to Lei et al. [32] the $\mathrm{BaMoO}_{4}$ crystals have a maximum PL emission at green region at 530 emission wavelength. These authors attributed that the particle size, crystalline degree, morphology, and surface defect are important factor to improvement of PL emission. Nogueira et al. [47], have observed that $\mathrm{BaMoO}_{4}$ crystals have a maximum PL emission at green region at 481 emission exited with a same wavelength and explained that

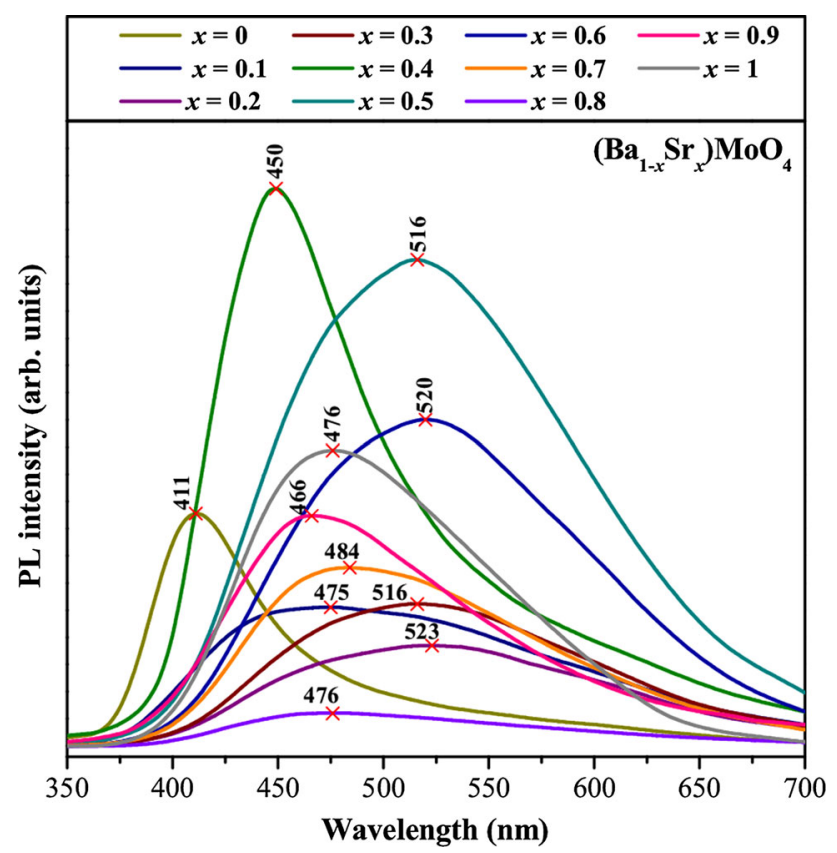

Fig. 7 PL emission spectra at room temperature for $\left(\mathrm{Ba}_{1-x} \mathrm{Sr}_{x}\right) \mathrm{MoO}_{4}$ ceramics with different $x$ concentrations the effects of structural order-disorder before and after arrival of the photon that could contribute significantly to PL emissions. Recently, Jena et al. [84] has not observed broadband issue for $\mathrm{BaMoO}_{4}$ crystals an attributed this behavior to large size of cation ionic radius, the greater is the parabola offset value is the probability of non-radiative electron relaxation from the exited state. We believe, that this behavior can be related to vibrational and vibronic relaxation related redistribution of energy due to high energy used in the excitation process $(\lambda=256 \mathrm{~nm})$. The PL emission spectra of $\left(\mathrm{Ba}_{1-x} \mathrm{Sr}_{x}\right) \mathrm{MoO}_{4}$ ceramics with $(x=0)$ is centered at $411 \mathrm{~nm}$ wavelength (Fig. 7). We attributed that our pure $\mathrm{BaMoO}_{4}$ ceramics have a particular PL emission in blue region due to presence of electronic levels characteristic of barium as $5 d$ orbitals empty in the conduction band. The replacement of $\mathrm{Ba}^{2+}$ ions by $\mathrm{Sr}^{2+}$ ions in $\left(\mathrm{Ba}_{1-x} \mathrm{Sr}_{x}\right) \mathrm{MoO}_{4}$ ceramics with $(x=0.1,0.2,0.3$, and 0.5$)$ promotes a great shift of maximum PL emission to green region at $(520,523,516$, and $516 \mathrm{~nm})$, respectively. However, we have noted only that $\left(\mathrm{Ba}_{1-x} \mathrm{Sr}_{x}\right) \mathrm{MoO}_{4}$ ceramics with $(x=0,4)$ exhibits the highest emission intensity of all ceramics and occurs a shift to the blue region. We explained this behavior due to shape of grains and simultaneous presence of polyhedrons and minor grains at higher grains at interface, which will be discussed on. Earlier it has been reported by Wei et al. [85] the blue PL spectra for $\mathrm{Ba}_{0.5} \mathrm{Sr}_{0.5} \mathrm{MoO}_{4}$ powders is related to might be the John-Teller effect degenerate the excited states of essentially $\left[\mathrm{MoO}_{4}\right]$ complex anion clusters of the slightly distorted tetragonal symmetry in $\mathrm{BaMoO}_{4}$. With increase in $\mathrm{Sr}^{2+}$ ion concentration in $\left(\mathrm{Ba}_{1-x} \mathrm{Sr}_{x}\right) \mathrm{MoO}_{4}$ ceramics enhanced charge-transfer mechanism in $\left[\mathrm{MoO}_{4}\right]$ clusters which shift the emission spectra towards green region. These green PL emission spectra were related to asymmetric distorted tetrahedral $\left[\mathrm{MoO}_{4}\right]$ clusters, distorted deltahedral $\left[\mathrm{BaO}_{8}\right]$ and distorted $\left[\mathrm{SrO}_{8}\right]$ clusters. These distorted clusters favor the population of intermediate levels within the band gap and stimulate the greenish emission. The small peak in red region in certain concentration may be due to some defect present in the bulk ceramics materials which leads to certain degree of disorder in the lattice. This type of disorder is common in molybdate $\left[\mathrm{MoO}_{4}\right]$ clusters intercalated to $\mathrm{Ba} / \mathrm{Sr}$ atoms is responsible for small peak in red region. Finally, we have observed that the $\left(\mathrm{Ba}_{1-x} \mathrm{Sr}_{x}\right) \mathrm{MoO}_{4}$ ceramics with $(x \leq 1)$ presents a tendency to a decrease in intensity of PL emission (Fig. 7).

\subsection{SEM image analyses}

Figure 8a-f illustrates the microstructural images of some composition for $\left(\mathrm{Ba}_{1-x} \mathrm{Sr}_{x}\right) \mathrm{MoO}_{4}$ ceramics $(x=0.0,0.4$, 

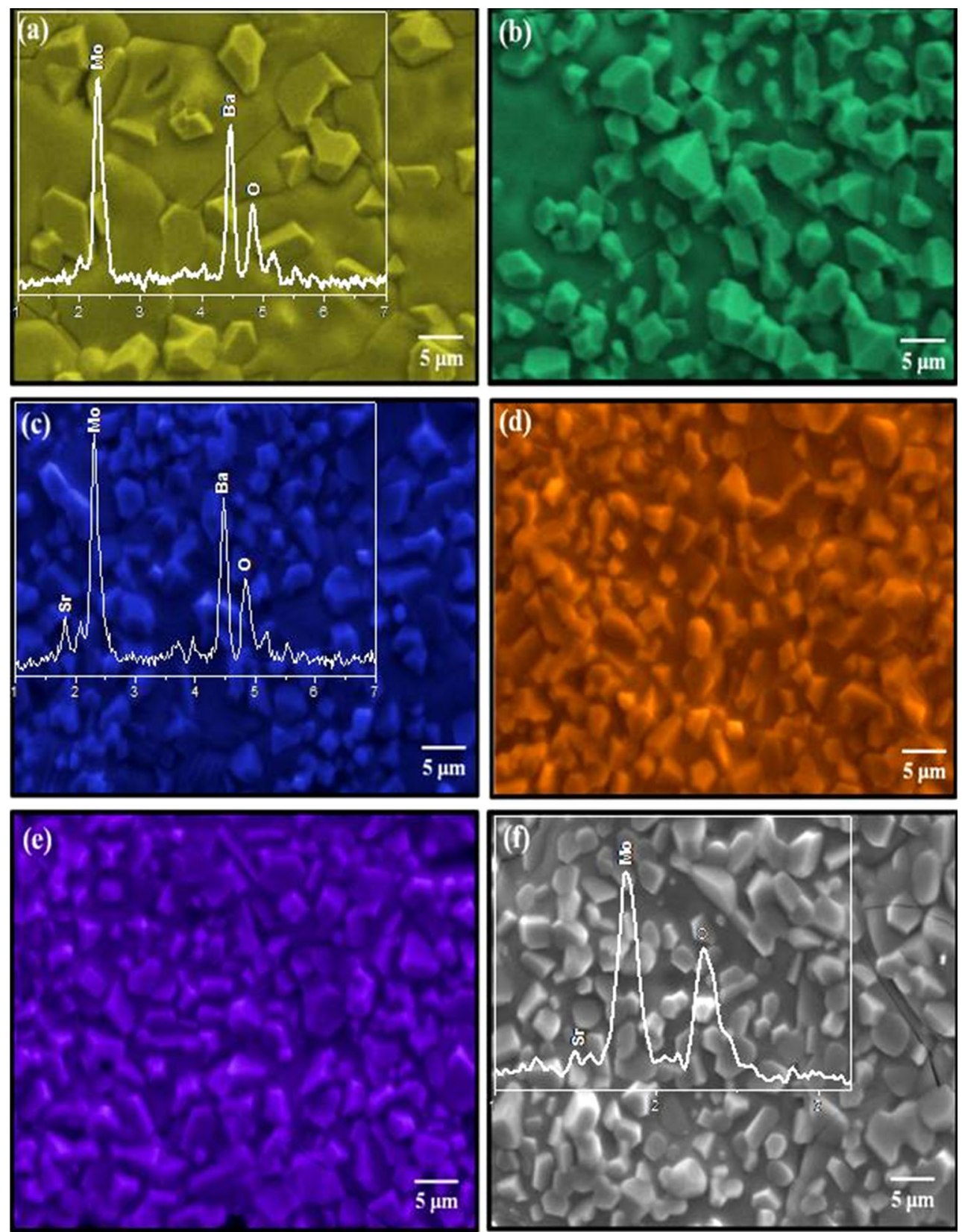

Fig. 8 SEM images for some concentrations with: a $x=0, \mathbf{b} x=0.4, \mathbf{c} x=0.6, \mathbf{d} x=0.7$, e $x=0.8$, and $\mathbf{f} x=1$. EDX spectra (inset) of $\mathrm{BaMoO}_{4}, \mathrm{Ba}_{0.4} \mathrm{Sr}_{0.6} \mathrm{MoO}_{4}$ and $\mathrm{SrMoO}_{4}$ compositions

$0.6,0.7,0.8$, and 1.0). The images indicated the presences of octahedral like are shown in Fig. 8a-f.

The particular shape is the nature characteristic morphology for scheelite types molybdate systems had been reported recently in many literatures [86, 87]. At intermediate concentration $x \leq 0.6$ of $\mathrm{Sr}^{2+}$ ion the number of octahedral grains and its sizes were increased, which indicated the inter diffusion start between the cations $\left(\mathrm{Ba}^{2+} /\right.$ $\left.\mathrm{Sr}^{2+}\right)$ and $\left[\mathrm{MoO}_{4}\right]^{2-}$ anions clusters leads to aggregates the grains and evolution of larger grains. Further increase of
$\mathrm{Sr}^{2+}$ ion concentration in the matrix (above $x=0.7$ ) retards the growth process and formation of irregular grains. In Fig. 8e, $\mathrm{f}$ for $\left(\mathrm{Ba}_{1-x} \mathrm{Sr}_{x}\right) \mathrm{MoO}_{4}$ ceramics with $(x=0.8$ and 1.0) appearance of smaller grains with irregular shapes along with octahedral grain size indicated that unlike $\mathrm{BaMoO}_{4}$ microstructure strontium doped $\mathrm{BaMoO}_{4}$ had higher self assembly growth process between grains because of the higher surface energy. The EDX spectra for some composition $(\mathrm{x}=0.0,0.6$ and 1.0$)$ to prove the chemical compositional are presented in the Fig. 8 (inset). 


\subsection{Dielectric and ferroelectric properties analyses}

Figure 9 shows the frequency dependence dielectric constant $\varepsilon^{\prime}$ (main) and dielectric loss tan $\delta$ (inset Fig. 9) at room temperature for some composition for $\left(\mathrm{Ba}_{1-x} \mathrm{Sr}_{x}\right)$ $\mathrm{MoO}_{4}$ ceramics $(x=0.0,0.2,0.4,0.8$, and 1.0$)$, both follows inverse dependence of frequency, normally followed by all ferroelectric materials.

Room temperature ferroelectric hysteresis loop analysis are recorded on sintered $\left(\mathrm{Ba}_{1-x} \mathrm{Sr}_{x}\right) \mathrm{MoO}_{4}$ ceramics to understand the nature of dielectric strength, switching polarization, coercive field and their correlation with orderdisorder in the lattice is shown in Fig. 9. The dielectric constant $\varepsilon$ ' of materials have four different polarization contributions: space charge polarization, dipolar polarization, ionic polarization and electronic polarization [88]. At lower frequency $(1 \mathrm{~Hz}-1 \mathrm{kHz})$ and at intermediate frequency $(1-100 \mathrm{kHz})$ ranges space charge polarization and dipolar polarization are dominated, respectively. Response of ionic and electronic polarizations is more than $100 \mathrm{kHz}$ and more than $1 \mathrm{GHz}$ respectively. It is observed that with increasing frequency the dielectric loss decreases sharply in frequency range $(1 \mathrm{~Hz}-1 \mathrm{kHz})$ and after $10 \mathrm{kHz}$ it is almost constant. This behavior mostly depends on space charge and dipole polarization effect in the systems. Earlier it was explained that in these materials the formation of defects and structural distortion in the lattice promotes by electronic density difference between the deltahedral $\left[\mathrm{BaO}_{8}\right] /\left[\mathrm{SrO}_{8}\right]$ clusters, which cause a dielectric loss. In pure $\mathrm{BaMoO}_{4}$ ceramics the defects and distortion are less compare to $\mathrm{Sr}^{2+}$ ions modified $\left(\mathrm{Ba}_{1-x} \mathrm{Sr}_{x}\right) \mathrm{MoO}_{4}$ ceramics. Therefore, the $\mathrm{Sr}^{2+}$ ions enhanced the structural disorder among different

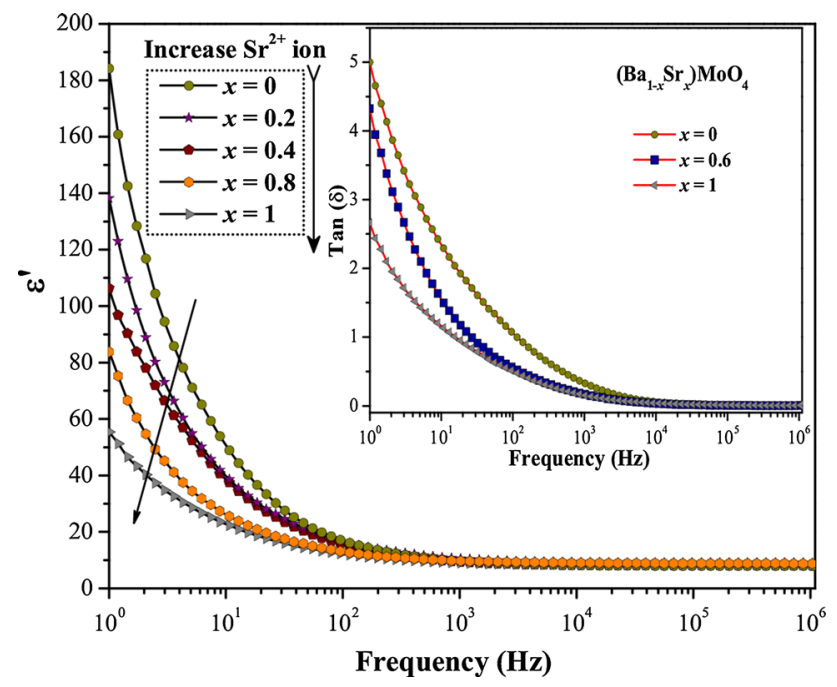

Fig. 9 Frequency dependence of dielectric constant $\left(\varepsilon^{\prime}\right)$ and loss factor $\left(\tan \delta\right.$, inset) of $\left(\mathrm{Ba}_{1-x} \mathrm{Sr}_{x}\right) \mathrm{MoO}_{4}$ ceramics for some concentrations with: $\mathbf{a} x=0, \mathbf{b} x=0.4, \mathbf{c} x=0.6, \mathbf{d} x=0.8$, and $\mathbf{e} x=1$ cations and anions clusters. These cations and anions in presence of oxygen vacancies transfer charge between clusters and slightly enhanced the conductivity in the scheelite materials.

The most common feature in ferroic-type of materials is the presence of the hysteresis loop due to spontaneous switching of domains with respect to applied electric field. The bulk symmetry of the materials plays an important role to determine the shape and size of the hysteresis loop. Typically the hysteresis loop through which the characteristic parameters such as saturation polarization $\left(P_{s}\right)$, remnant polarization $\left(P_{r}\right)$, coercive field $\left(E_{c}\right)$ can be determined. In reality the shape of the hysteresis loop depends on number of factors such as thickness of the sample, material composition, presence of disorder in the sample, thermal treatment, grain size, mechanical stress and so on $[89,90]$. Their effects on the material properties could well be reflected through the hysteresis loop. If the direction of spontaneous polarization in the material is random or distributed in such a way that the net microscopic polarization is zero such materials will not exhibit any ferroelectric hysteresis effect, which requires at least non-centrosymmetric (except cubic) symmetry of the material. This concept highlighted the existence of nonzero polarization or ferroelectric hysteresis in this scheelite-type tetragonal structure.

The Fig. 10a-d illustrate the macroscopic polarization $(P)$ state for $\left(\mathrm{Ba}_{1-x} \mathrm{Sr}_{x}\right) \mathrm{MoO}_{4}$ ceramics $(x=0.0,0.2,0.4$, 0.8 , and 1.0) induced by applying electric field $(\mathrm{E}=5,15$, 25 and $35 \mathrm{kV}$ ) at room temperature which is increased gradually by increasing the electric field strength.

In these particular material the $P-E$ hysteresis loops is more complex as conductivity is coexisting with normal ferroelectric which normally deteriorates the ferroelectricity if the conductivity is large [91]. According to the Fig. 10a, $b$ at intermediate concentration $(x \leq 0.6)$ the conductivity are dominated effect which transform hysteresis loop into round type of loop and so sign of saturation polarization are observed in these materials. The presence of conductivity in hysteresis loop through another way that is a large gap between the starting and ending points of the applied electric field. Large discrepancy between starting and ending electric field is so called "gap" is high at intermediate concentration might be due to higher disorder at cation and anion sites and the existence of free charge carrier in the matrix. In Fig. 10c, d can be observed a slim hysteresis loop to high concentration of $\mathrm{Sr}^{2+}$ ions in $\left(\mathrm{Ba}_{1-x} \mathrm{Sr}_{x}\right) \mathrm{MoO}_{4}$ ceramics and for pure $\mathrm{SrMoO}_{4}$ ceramics, which indicates a increase in lattice symmetry of bulk material. As mention in the earlier section that shrinkage of unit cell volume with strontium ion and modified the $c / a$ ratio in the lattice, hence reduces the tetragonal symmetry. In addition the grain size had an 


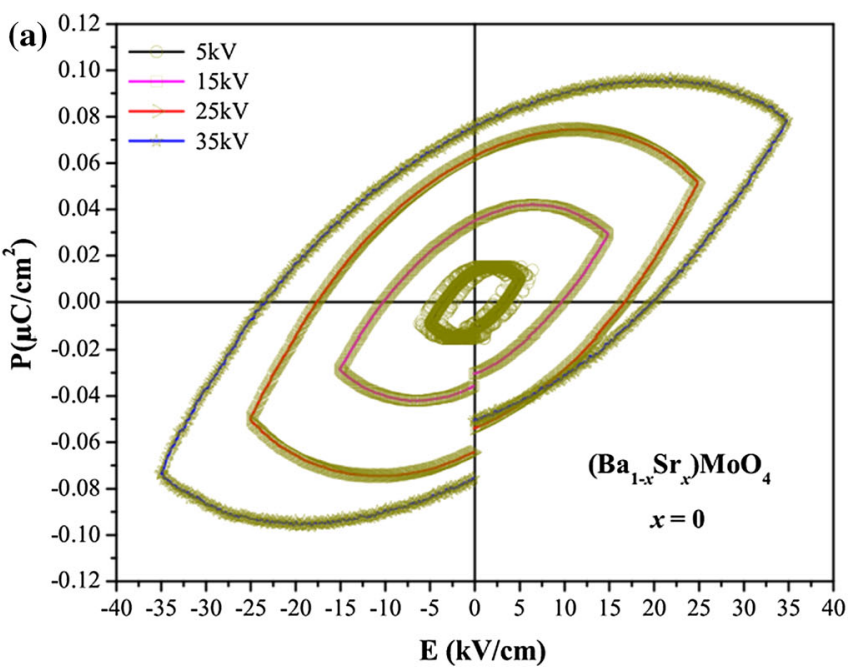

(b)
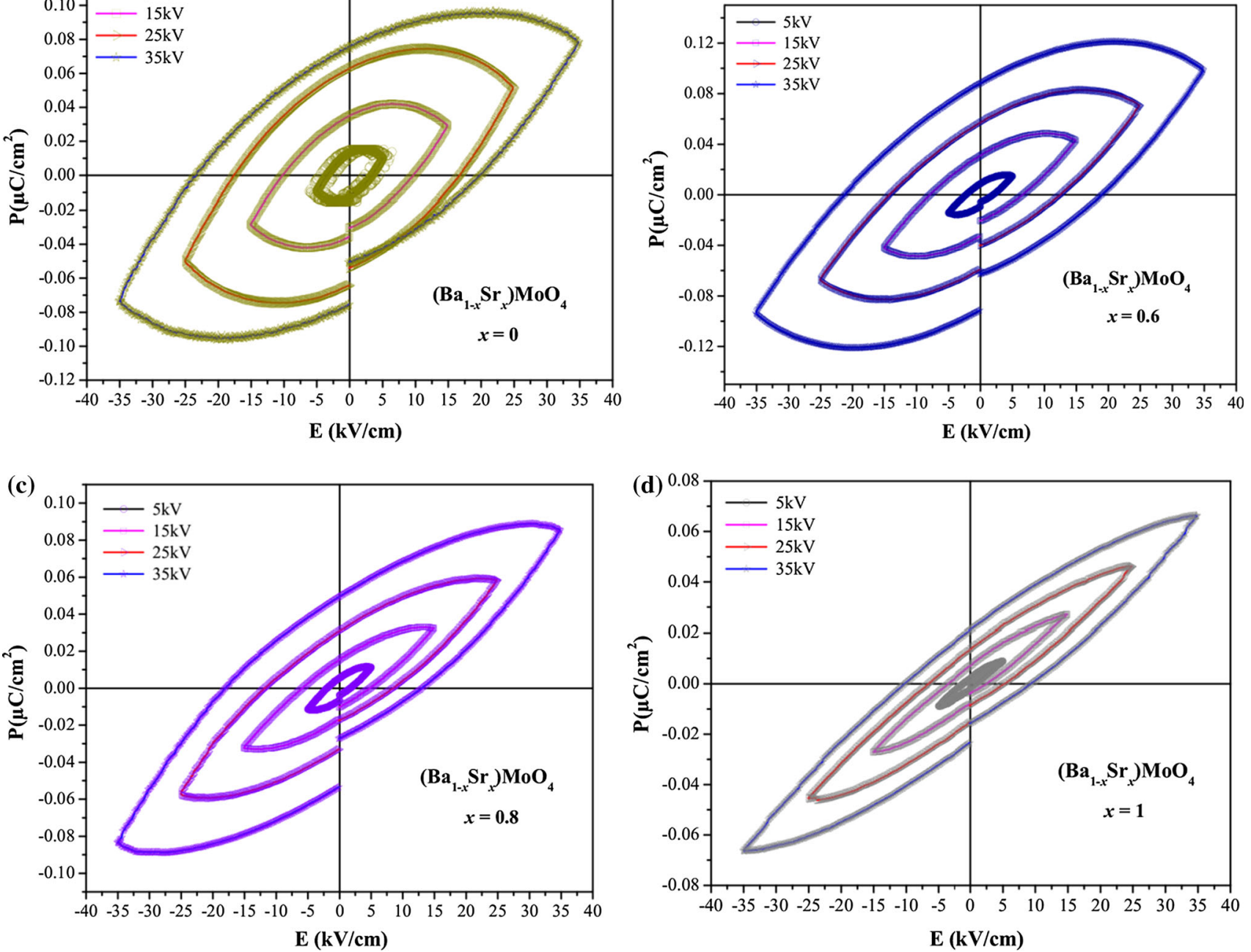

Fig. $10 \mathrm{P}-\mathrm{E}$ hysteresis loop of $\left(\mathrm{Ba}_{1-x} \mathrm{Sr}_{x}\right) \mathrm{MoO}_{4}$ ceramics for some concentrations with: a $x=0, \mathbf{b} x=0.4$, c $x=0.6$, d $x=0.8$, and e $x=1$

effect on the shape of hysteresis loop. When grain size is large the area of the loop is large as compare to the smaller grain. The competitive interaction between reduce lattice symmetry and grain sizes had a major cause for narrow hysteresis loop in higher concentration of strontium ion.

The microwave dielectric constant for $\left(\mathrm{Ba}_{1-x} \mathrm{Sr}_{x}\right) \mathrm{MoO}_{4}$ ceramics were measured by Hakki-Coleman method [92] at a respective frequency range vary in between 9 and $12 \mathrm{GHz}$. Permittivity $\left(\varepsilon_{r}\right)$, temperature coefficient resonant frequency $\left(\tau_{f}\right)$, quality factor $(Q \times f)$ and loss tangent $(\tan$ $\delta$ ) values of the sintered pellets were measured using $\mathrm{TE}_{01 \delta}$ resonance mode of dielectric resonator. The values of selected concentration are listed in Table 3.

In this table, we can note that with increase in the $\mathrm{Sr}^{2+}$ ion the values of the dielectric constant are decreases. According to the Shannon [93] additive rule, the substitution of lower polarizability $\alpha\left(\mathrm{Sr}^{2+}\right)=4.24 \AA^{3}$ ion in place of higher polarizability $\alpha\left(\mathrm{Ba}^{2+}\right)=6.40 \AA^{3}$, the dielectric constant should decrease which is observed in our present study. As already mention Hakki-Coleman $\mathrm{TE}_{01 \delta}$ resonance mode method has been found for suitable for real dielectric constant is given by Eq. (8):

$\varepsilon_{r}=1+\left(\frac{c}{\pi D f 1}\right)\left(\alpha_{1}^{2}+\beta_{1}^{2}\right)$

where, $c$ is the velocity of the light, $\alpha_{1}$ is given by chart mode and $\beta_{1}$ is obtained from resonance frequency $\left(f_{1}\right)$ and the simple dimension. The temperature coefficient of dielectric resonator were measured using temperature controlled hot plate in the temperature range of $25-75{ }^{\circ} \mathrm{C}$ using the following Eq. (9):

$\tau_{\varepsilon}=\left(\frac{1}{f}\right)\left(\frac{\Delta f}{\Delta T}\right)$

where, $(\Delta f / \Delta T)$ is the resonant frequency change with respect to temperature. The dielectric constant is also 
Table 3 Dielectric constant $\left(\varepsilon_{r}\right)$, molar volume $\left(V_{m}\right)$, quality factor $(Q \times f)$, temperature coefficient of resonance frequency $\left(\tau_{f}\right)$ and dielectric loss $(\tan \delta)$ for selected $x$ concentration of $\left(\mathrm{Ba}_{1-x} \mathrm{Sr}_{x}\right) \mathrm{MoO}_{4}$ ceramics materials

\begin{tabular}{llllll}
\hline$\left(\mathrm{Ba}_{1-x} \mathrm{Sr}_{x}\right) \mathrm{MoO}_{4}$ & $\varepsilon_{\mathrm{r}}$ & $\mathrm{V}_{\mathrm{m}}\left(\AA^{3}\right)$ & $\tau_{\mathrm{f}}\left(\mathrm{ppm} /{ }^{\circ} \mathrm{C}\right)$ & $\mathrm{Q} \times \mathrm{f}(\mathrm{GHz})$ & $\tan \delta\left(\times 10^{-3}\right)$ \\
\hline$x=0.1$ & 11.544 & 97.72 & -37.45 & 2819.69 & 3.59 \\
$x=0.2$ & 11.785 & 95.98 & -24.78 & 3212.81 & 3.18 \\
$x=0.5$ & 11.511 & 93.16 & -24.67 & 2259.04 & 4.56 \\
$x=0.7$ & 11.280 & 91.03 & -24.82 & 3218.59 & 3.16 \\
$x=1$ & 11.263 & 87.77 & -18.60 & 2633.37 & 3.87 \\
\hline
\end{tabular}

depends on the molar volume, secondary phases, density and ionic polarizability [94] of the compounds. Structural and microstructural analyses have no evidence of any secondary phases in these materials. Bulk density and porosity correction were applied to calculate the exact values of dielectric constant as shown in Eq. (10):

$\varepsilon_{r}=\varepsilon^{o b s}(1+1.5 P), \quad$ and $\quad P=1-\left(\frac{\rho}{\rho_{t h}}\right)$

where, $P$ is the porosity of the materials. Slightly random variation in quality factor $(Q \times f)$ [95] and temperature coefficient of resonance frequency $\left(\tau_{\mathrm{f}}\right)$ with $\mathrm{x}$ content in the compounds. This variation is most probably due to porosity in the samples and the above porosity correction is not applied to the values of the quality factor and $\tau_{f}$. Generally the values of $\tau_{f}$ are depends on coefficient of thermal expansion $\left(\alpha_{1}\right)$ and temperature coefficient of dielectric constant $\left(\tau_{\varepsilon}\right)$ of the sample as given by following Eq. (11) below:

$\tau_{f}=-\alpha_{1}-\frac{1}{2} \tau_{\varepsilon}$

The $\tau_{\varepsilon}$ has strong effect with lattice energy and unit cell volume of the materials. The combined effect of all the above mention parameters are determined the electrical properties of the ceramic materials over a wide microwave frequency range which is very much similar to the earlier reported values of dielectric constant in other wolframite and/or scheelite-types of structure [96-98].

\section{Conclusion}

In summary, we have obtained with success monophasic $\left(\mathrm{Ba}_{1-x} \mathrm{Sr}_{x}\right) \mathrm{MoO}_{4}$ ceramics with different $(x)$ compositions at $1000{ }^{\circ} \mathrm{C}$ by the solid state reactions method. XRD patterns and Micro-Raman spectra indicate that all $\left(\mathrm{Ba}_{1-x}\right.$ $\left.\mathrm{Sr}_{x}\right) \mathrm{MoO}_{4}$ ceramics are ordered at long and short range with a scheelite-type tetragonal structure. Rietveld refinement data show that all ceramics obtained which form a solid solution were perfect and occurred with a decrease in lattice parameters and unit-cell volume following the increase of $(x)$ in the lattice. Moreover, these data were employed to model $\left[\mathrm{BaO}_{8}\right],\left[\mathrm{SrO}_{8}\right]$ and $\left[\mathrm{MoO}_{4}\right]$ clusters by using lattice parameters and atomic positions. Raman-active modes reveal typical symmetric stretching and bending vibrations of tetrahedral $\left[\mathrm{MoO}_{4}\right]$ clusters and deltahedral $\left[\mathrm{BaO}_{8}\right] /\left[\mathrm{SrO}_{8}\right]$ clusters. UV-Vis diffuse reflectance spectra indicate that the substitution of $\mathrm{Ba}^{2+}$ by $\mathrm{Sr}^{2+}$ ions promotes a decrease in optical band gap values due to the appearance of intermediary energy levels within the band gap. PL spectra presented a broad-band profile typical of a system in which relaxation occurs by several paths involving the participation of numerous states within the band gap of the material. We suggested that these states are related to the defects associated to symmetry breaks between the deltahedral $\left[\mathrm{BaO}_{8}\right] /\left[\mathrm{SrO}_{8}\right]$ and $\left[\mathrm{MoO}_{4}\right]$ clusters and surface defects at medium range. The interplay between these clusters and defects generates a specific PL emission color. SEM images indicated that the increase of the $\mathrm{Sr}^{2+}$ ions promotes leads a decrease in average grain size and promotes a change to near-spherical grains. Moreover, the appearance of poly-disperse grains lead to both size and shape due to inhomogeneous grain growth. Evolution of $\mathrm{P}-\mathrm{E}$ hysteresis loop at room temperature highlighted the ferroelectric behavior in these materials. The shape and sizes of the loop are correlated with change in lattice parameters and $c / a$ ratio in the system. Slim hysteresis loop at higher strontium concentration indicated the decrease in tetragonal symmetry. In particular at intermediate concentration hysteresis loop is more complex as conductivity is coexisting with normal ferroelectric. Dipole interaction is dominating effect at intermediate frequency range which controls the value of dielectric constant and dielectric loss in these materials. The microwave dielectric properties such as dielectric constant, dielectric loss and quality factor and temperature coefficient of dielectric constant are correlated with change in molar volume, lattice constant and contraction of unit cell volume in these materials.

Acknowledgments Indian authors gratefully acknowledge the financial support from DST Fast Track project (F. No. SB/FT/CS-044/2013) Govt. of India. The Brazilian authors acknowledge the financial support of agencies: CNPq (304531/2013-8) and FAPESP (2012/14004-5). 


\section{References}

1. G. Davidson, Spectroscopic Properties of Inorganic and Organometallic Compounds (Royal Society of Chemistry, Great Britain, 1998), pp. 1-303

2. L.S. Cavalcante, F.M.C. Batista, M.A.P. Almeida, A.C. Rabelo, I.C. Nogueira, N.C. Batista, J.A. Varela, M.R.M.C. Santos, E. Longo, M. Li, Structural refinement, growth process, photoluminescence and photocatalytic properties of $\left(\mathrm{Ba}_{1-x} \mathrm{Pr}_{2 x / 3}\right) \mathrm{WO}_{4}$ crystals synthesized by the coprecipitation method. RSC Adv. 2 , 6438-6454 (2012)

3. R.C. Pullar, S. Farrah, N.M. Alford, $\mathrm{MgWO}_{4}, \mathrm{ZnWO}_{4}, \mathrm{NiWO}_{4}$ and $\mathrm{CoWO}_{4}$ microwave dielectric ceramics. J. Eur. Ceram. Soc. 27, 1059-1063 (2007)

4. I.L.V. Rosa, A.P.A. Marques, M.T.S. Tanaka, D.M.A. Melo, E.R. Leite, E. Longo, J.A. Varela, Synthesis, characterization and photophysical properties of $\mathrm{Eu}^{3+}$ doped in $\mathrm{BaMoO}_{4}$. J. Fluoresc. 18, 239-245 (2008)

5. A.J. Peter, I.B.S. Banu, Synthesis and luminescent properties of $\mathrm{Tb}^{3+}$ activated $\mathrm{AWO}_{4}$ based $(\mathrm{A}=\mathrm{Ca}$ and $\mathrm{Sr})$ efficient green emitting phosphors. J. Mater. Sci. Mater. Electron. 25, 2771-2779 (2014)

6. R. Sundaram, K. Nagaraja, Electrical and humidity sensing properties of lead (II) tungstate-tungsten (VI) oxide and zinc(II) tungstate-tungsten(VI) oxide composites. Mater. Res. Bull. 39, 581-590 (2004)

7. L. You, Y. Cao, Y.F. Sun, P. Sun, T. Zhang, Y. Du, G.Y. Lu, Humidity sensing properties of nanocrystalline $\mathrm{ZnWO}_{4}$ with porous structures. Sensors Actuators B Chem. 161, 799-804 (2012)

8. D.W. Kim, I.-S. Cho, S.S. Shin, S. Lee, T.H. Noh, D.H. Kim, H.S. Jung, K.S. Hong, Electronic band structures and photovoltaic properties of $\mathrm{MWO}_{4}(\mathrm{M}=\mathrm{Zn}, \mathrm{Mg}, \mathrm{Ca}, \mathrm{Sr})$ compounds. J. Solid State Chem. 184, 2103-2107 (2011)

9. M. Gancheva, A. Naydenov, R. Iordanova, D. Nihtianova, P. Stefanov, Mechanochemically assisted solid state synthesis, characterization, and catalytic properties of $\mathrm{MgWO}_{4}$. J. Mater. Sci. 50, 3447-3456 (2015)

10. L.S. Cavalcante, E. Moraes, M.A.P. Almeida, C.J. Dalmaschio, N.C. Batista, J.A. Varela, E. Longo, M. Siu Li, J. Andrés, A. Beltrán, A combined theoretical and experimental study of electronic structure and optical properties of $\beta$-ZnMoO4 microcrystals. Polyhedron 54, 13-25 (2013)

11. S.M.M. Zawawi, R. Yahya, A. Hassan, H.N.M.E. Mahmud, M.N. Daud, Structural and optical characterization of metal tungstates $\left(\mathrm{MWO}_{4} ; \mathrm{M}=\mathrm{Ni}, \mathrm{Ba}, \mathrm{Bi}\right)$ synthesized by a sucrose-templated method. Chem. Cent. J. 7, 80-89 (2013)

12. M.R.D. Bomio, L.S. Cavalcante, M.A.P. Almeida, R.L. Tranquilin, N.C. Batista, P.S. Pizani, M. Siu Li, J. Andres, E. Longo, Structural refinement, growth mechanism, infrared/Raman spectroscopies and photoluminescence properties of $\mathrm{PbMoO}_{4}$ crystals. Polyhedron 50, 532-545 (2013)

13. M.A.P. Almeida, L.S. Cavalcante, C. Morilla-Santos, C.J. Dalmaschio, S. Rajagopal, M. Siu Li, E. Longo, Effect of partial preferential orientation and distortions in octahedral clusters on the photoluminescence properties of $\mathrm{FeWO}_{4}$ nanocrystals. Cryst. Eng. Commun. 14, 7127-7132 (2012)

14. M.M.J. Sadiq, A.S. Nesaraj, Soft chemical synthesis and characterization of $\mathrm{BaWO}_{4}$ nanoparticles for photocatalytic removal of Rhodamine B present in water sample. J. Nanostruct. Chem. 5, 45-54 (2015)

15. X. Liu, L. Li, H.M. Noh, J.H. Jeong, K. Jang, D.S. Shin, Controllable synthesis of uniform CaMoO4:Eu 3+, M+(M= Li, Na, $\mathrm{K})$ microspheres and optimum luminescence properties. RSC Adv. 5, 9441-9454 (2015)
16. V.S. Marques, L.S. Cavalcante, J.C. Sczancoski, A.F.P. Alcântara, M.O. Orlandi, E. Moraes, E. Longo, J.A. Varela, M. Siu Li, M.R.M.C. Santos, Effect of different solvent ratios (water/ethylene glycol) on the growth process of $\mathrm{CaMoO}_{4}$ crystals and their optical properties. Cryst. Growth Des. 10, 4752-4768 (2010)

17. J. Guo, D. Zhou, L. Wang, H. Wang, T. Shao, Z.M. Qi, X. Yao, Infrared spectra, Raman spectra, microwave dielectric properties and simulation for effective permittivity of temperature stable ceramics $\mathrm{AMoO}_{4}-\mathrm{TiO}_{2} \quad(\mathrm{~A}=\mathrm{Ca}, \mathrm{Sr})$. Dalton Trans. 42, 1483-1491 (2013)

18. A. Priya, E. Sinha, S.K. Rout, Structural, optical and microwave dielectric properties of $\mathrm{Ba}_{1-x} \mathrm{Sr}_{x} \mathrm{WO}_{4}$ ceramics prepared by solid state reaction route. Solid State Sci. 20, 40-45 (2013)

19. V.D. Araújo, R.L. Tranquilin, F.V. Motta, C.A. Paskocimas, M.I.B. Bernardi, L.S. Cavalcante, J. Andres, E. Longo, M.R.D. Bomio, Effect of polyvinyl alcohol on the shape, photoluminescence and photocatalytic properties of $\mathrm{PbMoO}_{4}$ microcrystals. Mater. Sci. Semicond. Process. 26, 425-430 (2014)

20. L.S. Cavalcante, V.M. Longo, J.C. Sczancoski, M.A.P. Almeida, A.A. Batista, J.A. Varela, M.O. Orlandi, E. Longo, M. Siu Li, Electronic structure, growth mechanism and photoluminescence of $\mathrm{CaWO}_{4}$ crystals". Cryst. Eng. Commun. 14, 853-868 (2012)

21. B.P. Singh, R.A. Singh, Color tuning in thermally stable $\mathrm{Sm}^{3+}$ activated CaWO4 nanophosphors. New J. Chem. (2015). doi:10. 1039/C4NJ01911C

22. M. Guzik, E. Tomaszewicz, S.M. Kaczmarek, J. Cybińska, H. Fuks, Spectroscopic investigations of $\mathrm{Cd}_{0.25} \mathrm{Gd}_{0.50} \square_{0.25} \mathrm{WO}_{4}$ : $\mathrm{Eu}^{3+}$ - a new promising red phosphor. J. Non-Cryst. Solids 356, 1902-1907 (2010)

23. A.F. Gouveia, J.C. Sczancoski, M.M. Ferrer, A.S. Lima, M.R.M.C. Santos, M. Li, R.S. Santos, E. Longo, L.S. Cavalcante, Experimental and theoretical investigations of electronic structure and photoluminescence properties of $\beta-\mathrm{Ag}_{2} \mathrm{MoO}_{4}$ microcrystals. Inorg. Chem. 53, 5589-5599 (2014)

24. A. Dias, Theoretical calculations and hydrothermal processing of bawo $_{4}$ materials under environmentally friendly conditions. J. Solut. Chem. 40, 1126-1139 (2011)

25. Y. Guo, G. Fan, Z. Huang, J. Sun, L. Wang, T. Wang, J. Chen, Determination of standard molar enthalpies of formation of $\mathrm{SrMoO}_{4}$ micro/nano structures. Thermochim. Acta 530, 116-119 (2012)

26. G. Bayer, H.-G. Wiedemann, Formation of scheelite $\left(\mathrm{CaWO}_{4}\right)$ and powellite $\left(\mathrm{CaMoO}_{4}\right)$ by displacement reactions. Thermochim. Acta 133, 125-130 (1988)

27. C. Bouzidi, N. Sdiri, A. Boukhachem, H. Elhouichet, M. Féri, Impedance analysis of $\mathrm{BaMo}_{1-x} \mathrm{~W}_{x} \mathrm{O}_{4}$ ceramics. Superlattices Microstruct. 82, 559-573 (2015)

28. X. He, M. Guan, Z. Li, T. Shang, N. Lian, Q. Zhou, Enhancement of fluorescence from $\mathrm{BaMoO}_{4}: \mathrm{Pr}^{3+}$ deep-red-emitting phosphor via codoping $\mathrm{Li}^{+}$and $\mathrm{Na}^{+}$ions. J. Am. Ceram. Soc. 94, 2483-2488 (2011)

29. B.K. Maji, H. Jena, K.V.G. Kutty, Effect of la-substitution on the electrical conductivity of $\mathrm{Sr}_{1-x} \mathrm{La}_{x} \mathrm{MoO}_{4+\delta}(x=0-0.3)$ compounds. J. Mater. Eng. Perform. 23, 3126-3132 (2014)

30. R. Cao, K. Chen, Q. Hu, W. Li, H. Ao, C. Cao, T. Liang, Synthesis and luminescence properties of $\mathrm{Sr}_{(1 x-y-z)} \mathrm{MoO}_{4}: x \mathrm{Eu}^{3+}$, $y \mathrm{Bi}^{3+}, z \mathrm{R}^{+}\left(\mathrm{R}^{+}=\mathrm{Li}^{+}, \mathrm{Na}^{+}\right.$, and $\left.\mathrm{K}^{+}\right)$phosphors. Adv. Powder Technol. 26, 500-504 (2015)

31. Y.-S. Cho, Y.-D. Huh, Preparation and optical properties of green-emitting BaMoO4:Tb3+, Na+ nanophosphors for transparent displays. Electron. Mater. Lett. 10, 1185-1189 (2014)

32. M. Lei, C.X. Ye, S.S. Ding, K. Bi, H. Xiao, Z.B. Sun, D.Y. Fan, H.J. Yang, Y.G. Wang, Controllable route to barium molybdate crystal and their photoluminescence. J. Alloys Compd. 639, 102-105 (2015) 
33. J. Diaz-Algara, J.C. Rendón-Angeles, Z. Matamoros-Veloza, K. Yanagisawa, J.L. Rodriguez-Galicia, J.M. Rivera-Cobo, Singlestep synthesis of $\mathrm{SrMoO}_{4}$ particles from $\mathrm{SrSO}_{4}$ and their anticorrosive activity. J. Alloys Compd. 607, 73-84 (2014)

34. G. Xing, Y. Li, Y. Li, Z. Wu, P. Sun, Y. Wang, C. Zhao, G. Wu, Morphology-controllable synthesis of $\mathrm{SrMoO}_{4}$ hierarchical crystallites via a simple precipitation method. Mater. Chem. Phys. 127, 465-470 (2011)

35. C. Zhang, L. Zhang, C. Song, G. Jia, S. Huo, S. Shen, Welldefined barium molybdate hierarchical architectures with different morphologies: controllable synthesis, formation process, and luminescence properties. J. Alloys Compd. 589, 185-191 (2014)

36. K.K. Aruna, R. Manoharan, Electrochemical hydrogen evolution catalyzed by $\mathrm{SrMoO} 4$ spindle particles in acid water. Int. J. Hydrog. Energy 38, 12695-12703 (2013)

37. A.P.A. Marques, D.M.A. de Melo, E. Longo, C.A. Paskocimas, P.S. Pizani, E.R. Leite, Photoluminescence properties of $\mathrm{BaMoO}_{4}$ amorphous thin films. J. Solid State Chem. 178, 2346-2353 (2005)

38. A.P.A. Marques, M.T.S. Tanaka, E. Longo, E.R. Leite, I.L.V. Rosa, The role of the Eu3+ concentration on the $\mathrm{SrMoO}_{4}$ : Eu phosphor properties synthesis characterization and photophysical studies. J. Fluoresc. 21, 893-899 (2011)

39. L.S. Cavalcante, J.C. Sczancoski, R.L. Tranquilin, J.A. Varela, E. Longo, M.O. Orlandi, Growth mechanism of octahedron-like $\mathrm{BaMoO}_{4}$ microcrystals processed in microwave-hydrothermal: Experimental observations and computational modeling. Particuology 7, 353-362 (2009)

40. S. Wannapop, T. Thongtem, S. Thongtem, Characterization of donut-like $\mathrm{SrMoO}_{4}$ produced by microwave-hydrothermal process. J. Nanomater. 2013, 474576-474581 (2013)

41. Z. Li, J. Du, J. Zhang, T. Mu, Y. Gao, B. Han, J. Chen, J. Chen, Synthesis of single crystal $\mathrm{BaMoO}_{4}$ nanofibers in CTAB reverse microemulsions. Mater. Lett. 59, 64-68 (2005)

42. Q. Gong, X. Qian, X. Ma, Z. Zhu, Large-scale fabrication of novel hierarchical 3D $\mathrm{CaMoO}_{4}$ and $\mathrm{SrMoO}_{4}$ mesocrystals via a microemulsion-mediated route. Cryst. Growth Des. 6, 1821-1825 (2006)

43. M. Yoshimura, M. Ohmura, W.-S. Cho, M. Yashima, M. Kakihana, Preparation and luminescence of crystallized $\mathrm{Ba}_{1-x} \mathrm{Sr}_{x}$ $\mathrm{MoO}_{4}$ solid-solution films by an electrochemical method at room temperature. Jpn. J. Appl. Phys. 36, L1229-L1231 (1997)

44. C.-T. Xia, V.M. Fuenzalida, R.A. Zarate, Electrochemical preparation of crystallized $\mathrm{Ba}_{1-x} \mathrm{Sr}_{x} \mathrm{MoO}_{4}$ solid-solution films at room-temperature. J. Alloys Compd. 316, 250-255 (2001)

45. D.J. Gao, D.Q. Xiao, J. Bi, P. Yu, W. Zhang, G.L. Yu, J.G. Zhu, Electrochemical deposition of $\mathrm{Ba}_{1-x} \mathrm{Sr}_{x} \mathrm{MoO}_{4}$ thin films at room temperature. MRS Proceedings 755, DD6.3 (2002)

46. M. Sahu, K. Krishnan, B.K. Nagar, D. Jain, M.K. Saxena, C.G.S. Pillai, S. Dash, Characterization and thermo physical property investigations on $\mathrm{Ba}_{1-x} \mathrm{Sr}_{x} \mathrm{MoO}_{4}(x=0,0.18,0.38,0.60,0.81,1)$ solid-solutions. J. Nucl. Mater. 427, 323-332 (2012)

47. I.C. Nogueira, L.S. Cavalcante, P.F.S. Pereira, M.M. de Jesus, J.M. Rivas Mercury, N.C. Batista, M.S. Li, E. Longo, Rietveld refinement, morphology and optical properties of $\left(\mathrm{Ba}_{1-x} \mathrm{Sr}_{x}\right)$ $\mathrm{MoO}_{4}$ crystals. J. Appl. Cryst. 46, 1434-1446 (2013)

48. V. Nassif, R.E. Carbonio, J.A. Alonso, Neutron diffraction study of the crystal structure of $\mathrm{BaMoO}_{4}$ : a suitable precursor for metallic $\mathrm{BaMoO}_{3}$ perovskite. J. Solid State Chem. 146, 266-270 (1999)

49. C. Bernuy-Lopez, M. Allix, C.A. Bridges, J.B. Claridge, M.J. Rosseinsky, $\mathrm{Sr}_{2} \mathrm{MgMoO}_{6-\delta}$ : structure, phase stability, and cation site order control of reduction. Chem. Mater. 19, 1035-1043 (2007)

50. B.H. Toby, EXPGUI, a graphical use interphase for GSAS. J. Appl. Crystallogr. 34, 210-221 (2001)
51. J.C. Sczancoski, L.S. Cavalcante, N.L. Marana, R.O. da Silva, R.L. Tranquilin, M.R. Joya, P.S. Pizani, J.A. Varela, J.R. Sambrano, M. Siu Li, E. Longo, J. Andrés, Electronic structure and optical properties of $\mathrm{BaMoO}_{4}$ powders. Curr. Appl. Phys. 10, 614-624 (2010)

52. A.L. Patterson, The Scherrer formula for X-ray particle size determination. Phys. Rev. 56, 978-982 (1993)

53. K. Momma, F. Izumi, VESTA 3 for three-dimensional visualization of crystal, volumetric and morphology data. J. Appl. Cryst. 44, 1272-1276 (2011)

54. K. Momma, F. Izumi, VESTA: a three-dimensional visualization system for electronic and structural analysis. J. Appl. Cryst. 41, 653-658 (2008)

55. P.F.S. Pereira, I.C. Nogueira, E. Longo, E.J. Nassar, I.L.V. Rosa, L.S. Cavalcante, Rietveld refinement and optical properties of $\mathrm{SrWO}_{4}: \mathrm{Eu}^{3+}$ powders prepared by the non-hydrolytic sol-gel method. J. Rare Earths 33, 113-128 (2015)

56. R.F. Gonçalves, L.S. Cavalcante, I.C. Nogueira, E. Longo, M.J. Godinho, J.C. Sczancoski, V.R. Mastelaro, I.M. Pinatti, I.L.V. Rosa, A.P.A. Marques, Rietveld refinement, cluster modelling, growth mechanism and photoluminescence properties of $\mathrm{CaWO}_{4}: \mathrm{Eu}^{3+}$ microcrystals. Cryst. Eng. Commun. 17, 1654-1666 (2015)

57. T.T. Basiev, A.A. Sobol, Y.K. Voronko, P.G. Zverev, Spontaneous Raman spectroscopy of tungstate and molybdate crystals for Raman lasers. Opt. Mater. 15, 205-216 (2000)

58. J.C. Sczancoski, L.S. Cavalcante, M.R. Joya, J.A. Varela, P.S. Pizani, E. Longo, $\mathrm{SrMoO}_{4}$ powders processed in microwavehydrothermal: Synthesis, characterization and optical properties. Chem. Eng. J. 140, 632-637 (2008)

59. T.T. Basiev, A.A. Sobol, P.G. Zverev, L.I. Ivleva, V.V. Osiko, R.C. Powell, Raman spectroscopy of crystals for stimulated Raman scattering. Opt. Mater. 11, 307-314 (1999)

60. Q. Gong, X. Qian, H. Cao, W. Du, X. Ma, M. Mo, Novel shape evolution of $\mathrm{BaMoO}_{4}$ microcrystals. J. Phys. Chem. B. 110, 19295-19299 (2006)

61. S.P. Culver, F.A. Rabuffetti, S. Zhou, M. Mecklenburg, Y. Song, B.C. Melot, R.L. Brutchey, Low-temperature synthesis of $\mathrm{AMoO}_{4}(\mathrm{~A}=\mathrm{Ca}, \mathrm{Sr}, \mathrm{Ba})$ scheelite nanocrystals. Chem. Mater. 25, 4129-4134 (2013)

62. P. Kubelka, F. Munk-Aussig, Ein beitrag zur optik der farbanstriche. Zeit. Fur. Tech. Physik. 12, 593-601 (1931)

63. M.L. Myrick, M.N. Simcock, M. Baranowski, H. Brooke, S.L. Morgan, J.N. Mccutcheon, The Kubelka-Munk diffuse reflectance formula revisited. Appl. Spectrosc. Rev. 46, 140-165 (2011)

64. R.A. Smith, Semiconductors, 2nd edn. (Cambridge University Press, London, 1978), p. 434

65. D. Errandonea, L. Gracia, R. Lacomba-Perales, A. Polian, J.C. Chervin, Compression of scheelite-type $\mathrm{SrMoO}_{4}$ under quasihydrostatic conditions: redefining the high-pressure structural sequence. J. Appl. Phys. 113, 123510-123519 (2013)

66. R. Vali, Electronic properties and phonon spectra of $\mathrm{SrMoO}_{4}$. Comput. Mater. Sci. 50, 2683-2687 (2011)

67. E. Longo, D.P. Volanti, V.M. Longo, L. Gracia, I.C. Nogueira, M.A.P. Almeida, A.N. Pinheiro, M.M. Ferrer, L.S. Cavalcante, J. Andres, Toward an understanding of the growth of Ag filaments on $\alpha-\mathrm{Ag} 2 \mathrm{WO} 4$ and their photoluminescent properties: a Combined experimental and theoretical study. J. Phys. Chem. C 118, 1229-1239 (2014)

68. L. Gracia, V.M. Longo, L.S. Cavalcante, A. Beltrán, W. Avansi, M.S. Li, V.R. Mastelaro, J.A. Varela, E. Longo, J. Andre, Presence of excited electronic state in $\mathrm{CaWO}_{4}$ crystals provoked by a tetrahedral distortion: an experimental and theoretical investigation. J. Appl. Phys. 110, 043501-043511 (2011) 
69. A.P. de Moura, L.H. de Oliveira, I.L.V. Rosa, C.S. Xavier, P.N. Lisboa-Filho, M.S. Li, F.A. La Porta, E. Longo, J.A. Varela, Structural, optical, and magnetic properties of $\mathrm{NiMoO}_{4}$ nanorods prepared by microwave sintering. Sci. World J. 2015, 315084-315091 (2015)

70. M.R.D. Bomio, R.L. Tranquilin, F.V. Motta, C.A. Paskocimas, R.M. Nascimento, L. Gracia, J. Andres, E. Longo, Toward understanding the photocatalytic activity of $\mathrm{PbMoO}_{4}$ powders with predominant (111), (100), (011), and (110) facets: a combined experimental and theoretical study. J. Phys. Chem. C 117, 21382-21395 (2013)

71. J. Zhang, L. Li, W. Zi, L. Zou, S. Gan, G. Ji, Size-tailored synthesis and luminescent properties of three-dimensional $\mathrm{BaMoO}_{4}$, $\mathrm{BaMoO}_{4}: \mathrm{Eu}^{3+}$ micron-octahedrons and micron-flowers via sonochemical route. Luminescence 30, 280-289 (2015)

72. S.S. Ding, M. Lei, H. Xiao, G. Liu, Y.C. Zhang, K. Huang, C. Liang, Y.J. Wang, R. Zhang, D.Y. Fan, H.J. Yang, Y.G. Wang, Morphology evolution and photoluminescence of barium molybdate controlled by poly (sodium-4-styrenesulfonate). J. Alloys Compd. 579, 549-552 (2013)

73. L. Li, R. Li, W. Zi, S. Gan, Hydrothermal synthesis and luminescent properties of color-tunable $\mathrm{Dy}^{3+}$ doped and $\mathrm{Eu}^{3+} / \mathrm{Tb}^{3+}$ co-doped $\mathrm{MMoO}_{4}(\mathrm{M}=\mathrm{Ca}, \mathrm{Sr}, \mathrm{Ba})$ phosphors. Phys. B 458, 8-17 (2015)

74. P. Jena, S.K. Gupta, V. Natarajan, M. Sahu, N. Satyanarayana, M. Venkateswarlu, Structural characterization and photoluminescence properties of sol-gel derived nanocrystalline $\mathrm{BaMoO}_{4}$ : $\mathrm{Dy}^{3+}$. J. Lumin. 158, 203-210 (2015)

75. S. Cho, Synthesis and luminescence properties of $\mathrm{SrMoO}_{4}: \mathrm{RE}^{3+}$ $(\mathrm{RE}=\mathrm{Eu}$ or $\mathrm{Tb}$ ) phosphors. J. Korean Phys. Soc. 64, 1529-1534 (2014)

76. J. Zhang, R. Li, L. Liu, L. Li, L. Zou, S. Gan, G. Ji, Selfassembled 3D sphere-like $\mathrm{SrMoO}_{4}$ and $\mathrm{SrMoO}_{4}: \mathrm{Ln}^{3+}(\mathrm{Ln}=\mathrm{Eu}$, $\mathrm{Sm}, \mathrm{Tb}$, Dy) microarchitectures: Facile sonochemical synthesis and optical properties. Ultrason. Sonochem. 21, 1736-1744 (2014)

77. C. Shivakumara, R. Saraf, $\mathrm{Eu}^{3+}$ activated $\mathrm{SrMoO}_{4}$ phosphors for white LEDs applications: Synthesis and structural characterization. Opt. Mater. 42, 178-186 (2015)

78. L. Li, Z. Leng, W. Zi, S. Gan, Hydrothermal synthesis of $\mathrm{SrMoO}_{4}: \mathrm{Eu}^{3+}, \mathrm{Sm}^{3+}$ phosphors and their enhanced luminescent properties through energy transfer. J. Electron. Mater. 43, 2588-2596 (2014)

79. V.M. Longo, L.S. Cavalcante, E.C. Paris, J.C. Sczancoski, P.S. Pizani, M. Siu Li, J. Andrés, E. Longo, J.A. Varela, Hierarchical assembly of $\mathrm{CaMoO} 4$ nano-octahedrons and their photoluminescence properties. J. Phys. Chem. C 115, 5207-5219 (2011)

80. Z. Xia, D. Chen, Synthesis and luminescence properties of $\mathrm{BaMoO}_{4}: \mathrm{Sm}^{3+}$ phosphors. J. Am. Ceram. Soc. 1401, 1397-1401 (2010)

81. A.P. de Azevedo Marques, D.M.A. De Melo, C.A. Paskocimas, P.S. Pizani, M.R. Joya, E.R. Leite, E. Longo, Photoluminescent $\mathrm{BaMoO}_{4}$ nanopowders prepared by complex polymerization method (CPM). J. Solid State Chem. 179, 671-678 (2006)

82. R.T. Lam, G. Blasse, Luminescence of barium molybdate $\left(\mathrm{BaMoO}_{4}\right)$. J. Chem. Phys. 71, 3549 (1979)
83. L.S. Cavalcante, M.A.P. Almeida, W. Avansi Jr, R.L. Tranquilin, E. Longo, N.C. Batista, V.R. Mastelaro, M. Siu Li, Cluster coordination and photoluminescence properties of $\alpha-\mathrm{Ag}_{2} \mathrm{WO}_{4}$ microcrystals. Inorg. Chem. 51, 10675-10687 (2012)

84. P. Jena, S.K. Gupta, V. Natarajan, O. Padmaraj, N. Satyanarayana, M. Venkateswarlu, On the photo-luminescence properties of sol-gel derived undoped and $\mathrm{Dy}^{3+}$ ion doped nanocrystalline scheelite type $\mathrm{AMoO}_{4}(\mathrm{~A}=\mathrm{Ca}, \mathrm{Sr}$ and $\mathrm{Ba})$. Mater. Res. Bull. 64, 223-232 (2015)

85. L. Wei, Y. Liu, Y. Lu, T. Wu, Morphology and Photoluminescence of $\mathrm{Ba}_{0.5} \mathrm{Sr}_{0.5} \mathrm{MoO}_{4}$ powders by a molten salt method. J. Nanomater. 2012, 398582-398587 (2012)

86. E. Ryu, Y. Huh, Synthesis of hierarchical self-assembled $\mathrm{BaMoO}_{4}$ microcrystals. Bull. Korean Chem. Soc. 29(2), 503-506 (2008)

87. C. Mao, J. Geng, X. Wu, J. Zhu, Selective synthesis and luminescence properties of self-assembled $\mathrm{SrMoO}_{4}$ superstructures via a facile sonochemical route. J. Phys. Chem. C 114, 1982-1988 (2010)

88. S. Devi, A.K. Jha, Structural, dielectric and ferroelectric properties of tungsten substituted barium titanate ceramics. Asian J. Chem. 21, S117-S124 (2009)

89. L. Jin, F. Li, S. Zhang, Decoding the fingerprint of ferroelectric loops: comprehension of the material properties and structures. J. Am. Ceram. Soc. 97, 1-27 (2014)

90. G.H. Haertling, Ferroelectric ceramics: history and technology. J. Am. Ceram. Soc. 82, 797-818 (1999)

91. K.M. Rabe, M. Dawber, Modern physics of ferroelectrics: essential background. Appl. Phys. 105, 1-30 (2007)

92. P.D. Hakki, B.W. Coleman, A dielectric resonator method of measuring inductive capacities in the millimeter range. IRE Trans. Microw. Theory Tech. 8, 402-410 (1960)

93. R.D. Shannon, Dielectric polarizabilities of ions in oxides and fluorides. J. Appl. Phys. 73(1), 348 (1993)

94. S.D. Ramarao, S.R. Kiran, V.R.K. Murthy, Structural, lattice vibrational, optical and microwave dielectric studies on $\mathrm{Ca}_{1-x}$ $\mathrm{Sr}_{x} \mathrm{MoO}_{4}$ ceramics with scheelite structure. Mater. Res. Bull. 56, 71-79 (2014)

95. S. Kobayashi, Y. Tanaka, Resonant modes of a dielectric rod resonator short-circuited at both ends by parallel conducting plates. IEEE Trans. Microw. Theory Techol. 28, 1077-1085 (1980)

96. G.K. Choi, J.R. Kim, S.H. Yoon, K.S. Hong, Microwave dielectric properties of scheelite $(\mathrm{A}=\mathrm{Ca}, \mathrm{Sr}, \mathrm{Ba})$ and wolframite $(\mathrm{A}=\mathrm{Mg}, \mathrm{Zn}, \mathrm{Mn}) \mathrm{AMoO}_{4}$ compounds. J. Eur. Ceram. Soc. 27, 3063-3067 (2007)

97. S.H. Yoon, D.W. Kim, S.Y. Cho, K.S. Hong, Investigation of the relations between structure and microwave dielectric properties of divalent metal tungstate compounds. J. Eur. Ceram. Soc. 26, 2051-2054 (2006)

98. D.A. Durilin, O.V. Ovchar, A.G. Belous, Effect of nonstoichiometry on the structure and microwave dielectric properties of $\mathrm{Ba}_{1-x}\left(\mathrm{Zn}_{1 / 2} \mathrm{~W}_{1 / 2}\right) \mathrm{O}_{3-x}$ and $\mathrm{Ba}\left(\mathrm{Zn}_{1 / 2-y} \mathrm{~W}_{1 / 2}\right) \mathrm{O}_{3-y / 2}$. Inorg. Mater. 47, 313-316 (2011) 